\title{
Title: Predicting effects of methylphenidate and sulpiride on brain and cognition: A pharmaco-fMRI, PET study: Design and descriptives
}

\author{
Authors: Jessica I. Määttä ${ }^{4}$, Ruben van den Bosch ${ }^{1,2 *}$, Danae Papadopetraki ${ }^{1,2 *}$, Lieke Hofmans ${ }^{1,2 *}$, \\ Britt Lambregts ${ }^{1,2}$, Andrew Westbrook ${ }^{3}$, Robbert-Jan Verkes ${ }^{2}$, Roshan Cools ${ }^{1,2}$ \\ Affiliation(s): \\ ${ }^{1}$ Donders Institute for Brain, Cognition and Behaviour, Donders Centre for Cognitive Neuroimaging, Radboud \\ University, Nijmegen, The Netherlands \\ ${ }^{2}$ Department of Psychiatry, Radboud University Medical Center, Nijmegen, The Netherlands \\ ${ }^{3}$ Department of Cognitive, Linguistics and Psychological Sciences, Brown University, Providence, RI, USA \\ ${ }^{4}$ Department of Clinical Neuroscience, Karolinska Institutet, Stockholm, Sweden \\ * These authors contributed equally to this work \\ Corresponding author: Jessica I. Määttä. E-mail: jessica.maatta@ki.se/jessica.i.maatta@gmail.com
}

Keywords: dopamine, PET, methylphenidate, sulpiride, mood, autonomic arousal, impulsivity, eye blink rate, working memory, dopamine synthesis capacity,

Funding: The work is supported by a Vici grant awarded to Roshan Cools from the Netherlands Organization for Scientific Research (Grant No. 453-14-015).

\begin{abstract}
:
The large variation observed in the effects of dopaminergic drugs poses a major problem for neuropsychiatry, where therapeutic drugs may be ineffective or detrimental in a proportion of patients, but also for the healthy population. We have conducted a pharmaco-fMRI/PET study in 100 healthy participants to investigate the neural and neurochemical mechanisms of this variability. We studied the cognitive effects of methylphenidate $(20 \mathrm{mg})$ and sulpiride $(400 \mathrm{mg})$ across various cognitive domains, such as reward learning and motivation, working memory and effort motivation. To establish the baseline dopamine-dependency of the drug effects, all participants underwent an $\left[{ }^{18} \mathrm{~F}\right] \mathrm{DOPA}$ positron emission tomography scan on a separate off-drug session to quantify their baseline striatal dopamine synthesis capacity. In addition, multiple putative proxy measures of striatal dopamine activity were acquired, including spontaneous eye blink rate, trait impulsivity, subjective reward sensitivity and working memory capacity. The drug effects on each of the cognitive paradigms and their potential dependency on dopamine synthesis capacity and putative proxy measures are reported in separate papers. In the present paper, we report the design of the full study, as well as drug effects on subjective mood and autonomic arousal. This report aims to serve as a reference for future pharmacological fMRI/PET studies as well as for the specific papers resulting from detailed analyses of the included cognitive paradigms. The study will enable the development of a proxy-model of baseline dopamine, intended to provide a pragmatic handle on predicting the effects of dopaminergic drugs on brain and cognition that maximally generalizes to new participants.
\end{abstract}




\section{Introduction}

Brain dopamine has been long implicated in a wide variety of cognitive functions, including motivation, learning and working memory, as well as a variety of neuropsychiatric disorders characterized by cognitive deficits, such as attention deficit hyperactivity disorder (ADHD) and schizophrenia. Such cognitive deficits are commonly treated with drugs that alter dopamine transmission, such as the catecholamine reuptake blocker methylphenidate or the dopamine $\mathrm{D}_{2}$ receptor antagonist sulpiride. Psychostimulants, such as methylphenidate, are the first-line medication treatment of $A D(H) D$, while antipsychotics, such as sulpiride, are used to treat symptoms of schizophrenia (Strange, 2001).

In line with the observation that methylphenidate can decrease symptoms of inattention and hyperactivity (Faraone \& Buitelaar, 2010), it has been shown to enhance behavioral and cognitive control (Li et al., 2010; Linssen, Vuurman, Sambeth, \& Riedel, 2012; Moeller et al., 2012; Nandam et al., 2011), memory (Clatworthy et al., 2009; Izquierdo et al., 2008; Linssen, Sambeth, Vuurman, \& Riedel, 2014; Linssen et al., 2012), error monitoring, reward/punishment learning (Barnes, O'Connell, Nandam, Dean, \& Bellgrove, 2013; Hester et al., 2012; van der Schaaf, Fallon, Ter Huurne, Buitelaar, \& Cools, 2013), attention and academic performance (Marcus \& Durkin, 2011; Wigal et al., 2011). Furthermore, methylphenidate $(20 \mathrm{mg}$ ) administration has been shown to increase positive mood, alertness, restlessness, and anxiety (for review see Repantis, Schlattmann, Laisney, \& Heuser, 2010), as well as indices of autonomic arousal, such as, heart rate and blood pressure (Cooper et al., 2005; Volkow et al., 2003).

However, the mechanisms by which methylphenidate alters cognition remain unclear. Methylphenidates effects on cognitive function might be mediated by dopamine (González-Burgos et al., 2002), but may also reflect changes in noradrenaline. After all methylphenidate acts via blocking both noradrenaline (Wall, Gu, \& Rudnick, 1995) and dopamine transporters (Volkow et al., 2001), thus decreasing the removal of noradrenaline and dopamine from the synaptic cleft, and increasing extracellular dopamine (Volkow et al., 2002) and noradrenaline levels (Berridge et al., 2006; Kuczenski \& Segal, 1997). Furthermore, methylphenidates cognitive effects might reflect increases in extracellular dopamine and noradrenaline in the prefrontal cortex (Spencer, Klein, \& Berridge, 2012), but might also reflect increases of dopamine in the striatum (Volkow, Wang, Fowler, \& Ding, 2005).

The first overarching aim of the present study was to directly address the striatal dopamine receptor selectivity of methylphenidate's effects, by directly comparing effects on the same tasks of methylphenidate with those of the more selective dopamine receptor agent sulpiride (Kuroki, Meltzer, \& Ichikawa, 1999; Strange, 2001). Sulpiride acts primarily on the striatum where $D_{2}$ receptor density is the highest (Mehta et al., 2003; Mehta, Manes, Magnolfi, Sahakian, \& Robbins, 2004). Dopamine $D_{2}$ receptors are located both pre- and post-synaptically (Farde, Halldin, \& Sedvall, 1987; Farde, Nordstrom, Wiesel, Halldin, \& Sedvall, 1989). At low doses, sulpiride paradoxically increases dopamine transmission, by binding to dopamine autoreceptors, thereby disinhibiting dopamine release from the presynaptic terminal (Ago, Nakamura, Baba, \& Matsuda, 2005; Chavanon, Wacker, \& Stemmler, 2013; Serra et al., 1990). Indeed sulpiride has also been shown to influence reward- versus punishment learning (Janssen, Sescousse, Hashemi, Timmer, et al., 2015; van der Schaaf et al., 2014), attentional set-switching and distractor-resistant working memory performance (Mehta et al., 2004). Conversely, sulpiride (400 mg \& $800 \mathrm{mg}$ ) administration has not been shown to influence mood or autonomic arousal (Janssen, Sescousse, Hashemi, Timmer, et al., 2015; Naef et al., 2017), although the number of studies assessing effects of sulpiride on mood and physiology in the healthy population is limited. 
Unfortunately, we already know there is huge variability in the direction and extent of the effects of dopaminergic drugs, both between and within different individuals (Cools and D'Esposito, 2011). This poses a major problem to neuropsychiatry, where therapeutic drugs may be ineffective or even detrimental in a proportion of patients (Brugger et al., 2020; Howes et al., 2009), as well as in the healthy population (Cools et al., 2009; Janssen, Sescousse, Hashemi, Harmina, et al., 2015; Mehta et al., 2004; van der Schaaf et al., 2014). Identification of factors that mediate this variability is of great importance to the development of individualized medicine and drug therapies; targeted at specific behavioral deficits as well as at specific individuals. Isolating the effect of dopamine on cognitive function requires taking into account individual differences in baseline levels of dopamine (Cools \& D'Esposito, 2011). Indeed prior work has established that effects of dopamine receptor agents can be predicted based on $\left[{ }^{18} \mathrm{~F}\right]$-fluoro-dopa $\left(\left[{ }^{18} \mathrm{~F}\right] \mathrm{DOPA}\right)$ PET imaging (Cools et al., 2009; Howes et al, 2009). The first overarching aim of the present study was to establish whether $\left[{ }^{18} \mathrm{~F}\right] \mathrm{DOPA}$ PET PET imaging can also be used to predict the cognitive effects of the most commonly used dopaminergic drug methylphenidate.

Unfortunately, PET is expensive, and often infeasible. Therefore, proxy-measures of dopamine have been used in order to account for variability in drug effects across different individuals. Such proxymeasures have included working memory capacity (Cools \& D'Esposito, 2011; Cools, Gibbs, Miyakawa, Jagust, \& D'Esposito, 2008; Cools, Sheridan, Jacobs, \& D'Esposito, 2007; Frank \& O'Reilly, 2006; Gibbs \& D'Esposito, 2005; Kimberg, D’Esposito, \& Farah, 1997; Landau, Lal, O'Neil, Baker, \& Jagust, 2009), personality traits (like impulsivity) (Buckholtz et al., 2010; Clatworthy et al., 2009; Cools et al., 2007), and eye-blink rate (Jongkees \& Colzato, 2016; Karson, 1983). However, the interdependency of these variables is currently unclear and the amount of variance explained by each variable separately is limited. Creating a proxy-model of dopamine would provide behavioral predictors of dopamine (synthesis capacity) that maximally generalizes to new participants, thereby offering a pragmatic handle on baseline-dependency and a tool that can be enormously beneficial to personalized healthcare and the international research community in general. The second overarching aim of the current study was to build such a proxy model of dopamine.

Finally, effects of dopaminergic drugs are also known to vary as a function of the task-context. This within-subject, across-task, variability is thought to reflect differential sensitivity of distinct neural systems to changes in dopamine, possibly reflecting distinct optimal levels of dopamine across neural systems (Cools and Robbins, 2004). Therefore, in order to predict the effects of dopaminergic drugs on behavior across individuals and task demands, it is important to isolate the neural locus of dopaminergic drug effects. To this end, all participants also underwent functional magnetic resonance imaging during the performance of key dopamine-related probes.

In this paper we provide a full accounting of the precise methods involved in collecting a large-sample $\left[{ }^{18} \mathrm{~F}\right]$ FDOPA PET/fMRI study, aimed at unraveling the neural and neurochemical mechanisms of variability in the cognitive effects of methylphenidate. Comparisons with the selective agent sulpiride allow inference about the dopamine receptor selectivity of methylphenidates effects. We also report drug effects on mood and autonomic arousal (i.e., blood pressure \& heart rate) to validate the drug manipulations. 


\section{Methods}

\subsection{Sample}

The sample consisted of 100 healthy participants. All participants were between $18-45$ years old (Mean $=23, \mathrm{SD}=5.04$, range: $18-43$ ), predominantly right-handed and native-Dutch speakers (for overview of sample see Figure 1). Gender balance was kept equal across the sample. Participants were recruited through advertisement and were financially compensated for their participation. Participants were excluded based on whether they met any of the exclusion criteria to ensure they had no relevant medical history, and participants agreed to abstain from alcohol and psychotropic medication and recreational drugs before each session (for further details see section 2.2.1). About 700 potential participants showed interest in the study, from whom 133 were invited for an intake session after a preliminary phone screening, and 100 participants were included in the final sample. Four participants dropped out during the study; two participants dropped out during the second session, one due to nausea and the other due to difficulties abstaining from caffeine, and two participants dropped out due to anxiety, after three and four sessions, respectively. Additionally, PET data of two other participants were incomplete (one due to scanner software issues and another due to discomfort during scanning). Participants could choose to take part in two additional, but not required, parts of the study; submit a saliva sample for genetic dopamine pathway analysis (via the Cognomics project already running at the center) and/or consent to a passive collection of coarse measures of smartphone use (Westbrook, Ghosh, van den Bosch, Määttä, Hofmans \& Cools, 2021). There were 18 and 29 participants out of the 100 participants that agreed to take part in these respective projects. Due to logging issues, smartphone use data from only 22 participants could be used for analysis, and due to a low number of submitted saliva samples $(n=18)$ no genetic dopamine pathway analysis will be explored. The study took place at the Centre for Cognitive Neuroimaging of the Donders Institute for Brain, Cognition and Behaviour and the Radboud University Medical Center in Nijmegen, The Netherlands. 
A

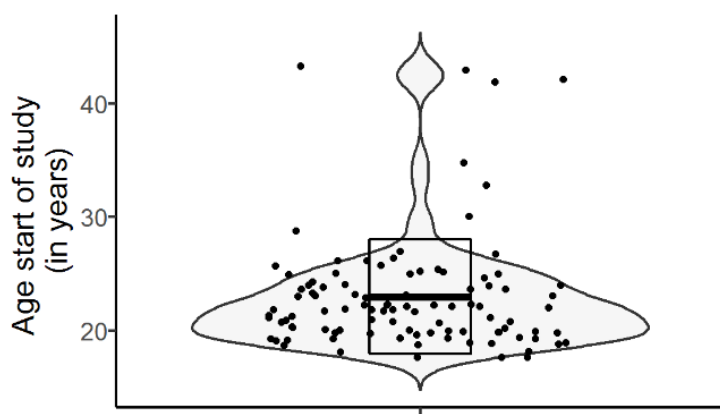

C

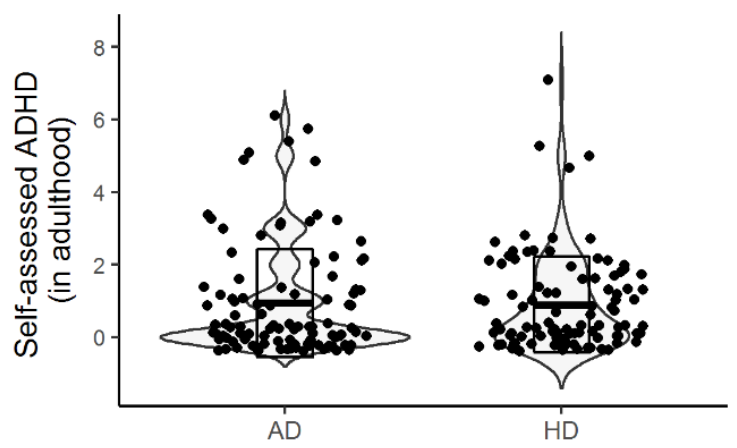

B

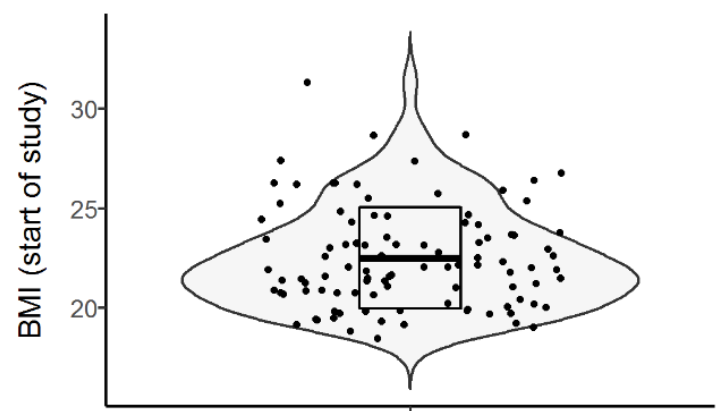

D

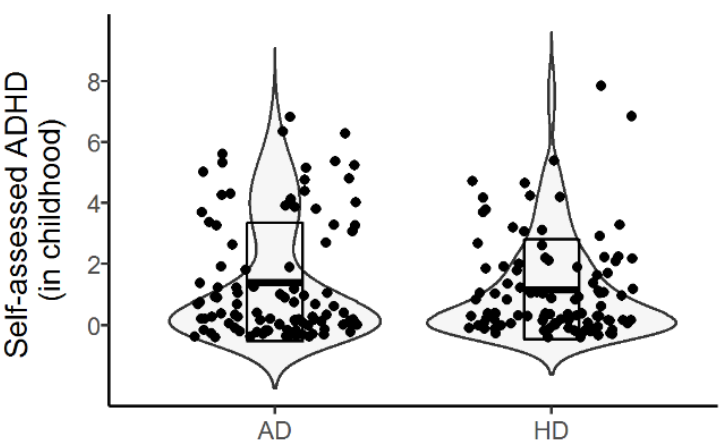

Figure 1. A. Distribution of age at the start of the study ( $\operatorname{Mean}=23, \operatorname{Min}=18, \operatorname{Max}=43, S D=5.04$ ), B. Mean body mass index (BMI) at the start of the study was 22.5 ( $\mathrm{Min}=18.5, \mathrm{Max}=31.4, \mathrm{SD}=2.55$ ). C. Self-reported inattention $(A D)$ symptoms in adulthood (Kooij \& Buitelaar, 1997), Mean $=.94, \mathrm{SD}=1.49$, Min $=.00$, Max $=6.00$ ) and self-reported hyperactivity (HD) symptoms in adulthood (Mean $=.90, \mathrm{SD}=1.17$, $\mathrm{Min}=.0, \mathrm{Max}=8.0$ ). D. Self-reported inattention (AD) symptoms in childhood (Kooij \& Buitelaar, 1997), Mean $=1.41, \mathrm{SD}=1.93, \mathrm{Min}=.0, \mathrm{Max}=7.0$ ) and self-reported hyperactivity (HD) symptoms in childhood (Mean $=1.17 \mathrm{SD}=1.64$, Min $=.0, \mathrm{Max}=8.0$ ). Score equal to 5 or higher corresponds to diagnosis in adulthood, while 6 or higher corresponds to diagnosis in childhood. Note that no participant reached the cut off for ADHD diagnosis at inclusion, assessed with M.I.N.I. Plus 5.0.0.

\subsection{Design}

The study had a within-subject, double-blind, placebo-controlled, cross-over design (data acquisition took place between the years 2017-2018). Included participants took part in five separate test sessions that were separated by at least one week (Figure 2): (1) one inclusion screening, (2-4) three pharmacofMRI sessions, and (5) one $\left[{ }^{18} \mathrm{~F}\right]$-fluoro-dopa $\left(\left[{ }^{18} \mathrm{~F}\right] \mathrm{DOPA}\right)$ PET session.

\section{Day 1}

During the inclusion screening, we established whether participants met the inclusion/exclusion criteria (section 2.2.1), and we acquired an anatomical MRI brain scan, as well as various baseline measures, such as working memory capacity (Daneman \& Carpenter, 1980, Groth-Marnat, 2001, Listening span and digit span, respectively), crystalized intelligence (NLV/NART, Crawford, Stewart, Cochrane, Parker, \& Besson, 1989; Schmand et al., 1991) and spontaneous eye blink rate. 


\begin{tabular}{|c|c|c|c|}
\hline DAY 1: INTAKE SCREENING & DAY 2-4: PHARMACO-fMRI & HOME: QUESTIONNAIRES & DAY 5: PET \\
\hline $\begin{array}{l}\text { COGNITIVE ASSESSMENT } \\
\text { Executive functions } \\
\text { Digit span (WM) } \\
\text { Listening span (WM) } \\
\text { Intellectual functioning } \\
\text { Crystalized intelligence } \\
\text { (NLV/NART) } \\
\text { HEALTH SCREENING } \\
\text { Psychiatric assessment } \\
\text { M.I.N.I. Plus 5.0.0 } \\
\text { Somatic measures } \\
\text { Electrocardiography (ECG) } \\
\text { Heart rate/blood pressure } \\
\text { Body temparture } \\
\text { MAGNETIC RESONANCE } \\
\text { IMAGING } \\
\text { Anatomical T1 scan } \\
\text { PHYSIOLOGICAL MEASURES } \\
\text { Eye blink rate (sEBR) }\end{array}$ & $\begin{array}{l}\text { COGNITIVE ASSESSMENT } \\
\text { Executive functions } \\
\text { Colorwheel working memory task } \\
\text { N-back working memory task } \\
\text { Cognitive motivation } \\
\text { Effort discounting } \\
\text { Reward processing } \\
\text { Reinforcement learning and } \\
\text { working memory (RLWM) } \\
\text { Creativity } \\
\text { Alternative Uses Task (AUT) } \\
\text { Remote Associates Task (RAT) } \\
\text { Alternative Names Task (ANT) } \\
\text { MAGNETIC RESONANCE IMAGING } \\
\text { Reward processing } \\
\text { Reversal learning task (RL) } \\
\text { Reward motivation } \\
\text { Monetary incentive delay task (MID) } \\
\text { SOMATIC MEASURES x } 3 \\
\text { Heart rate/blood pressure } \\
\text { Body temperature } \\
\text { MOOD ASSESSMENT x } 3 \\
\text { Positive and negative mood Scales (PANAS) } \\
\text { Visual analouge Scale (VAS) }\end{array}$ & $\begin{array}{l}\text { PERSONALITY ASSESSMENT } \\
\text { Impulisivity } \\
\text { Trait impulsivity (BIS-11) } \\
\text { Motivational tendencies } \\
\text { Behavioral/inhibition } \\
\text { activation (BIS/BAS) } \\
\text { Tendency for effortful } \\
\text { engagement } \\
\text { Need for cognition (NCS) } \\
\text { OTHER ASSESSMENTS } \\
\text { Mood assessment } \\
\text { Depression inventory (BDI) } \\
\text { Creativity assessment } \\
\text { Self-reported creativity } \\
\text { (K-DOCS) }\end{array}$ & $\begin{array}{l}\text { COGNITIVE ASSESSMENT } \\
\text { Executive functions } \\
\text { Digit span (WM) } \\
\text { Intellectual functioning } \\
\text { Fluid intelligence (WAIS-IV-NL) } \\
\text { Motivation/learning } \\
\text { Pavlovian to instrumental } \\
\text { transfer task (PIT) } \\
\\
\text { POSITRON EMISSION } \\
\text { TOMOGRAPHY (PET) } \\
\text { Dopamine synthesis capacity } \\
\text { [18F]DOPA PET SCAN }\end{array}$ \\
\hline
\end{tabular}

Figure 2. This figure displays which assessment took place on which day of the study. The assessments are categorized by type of task, not by order of administration. Note that participants were administered either the Color wheel or the N-back working memory task on day 2-4. Each participant completed the five sessions within 90 days on average (SD = 31, Range: 38-227 days). WM: Working memory. For more details see sections 2.2.1 - 2.2.6.

Day 2-4

During the three pharmaco-fMRI testing sessions participants received one oral capsule of either, methylphenidate (MPH, 20mg), sulpiride (SUL, 400mg) or placebo. The order of administration was randomized (rather than counterbalanced as originally planned, due to a communication error; the error was only discovered at the stage of deblinding, see the orders and their appearance in Table 1B, see further in supplementary figures 5-8). Each session started with a short medical screening. A pregnancy test was performed for female participants before drug administration, and vital signs monitoring consisting of physiological measures (section 2.2.5) were taken together with mood ratings (section 2.2.6) at three occasions throughout each pharmaco-fMRI session for safety reasons. On each session, seven cognitive task paradigms were administered in and outside the fMRI scanner (section 2.2.2), assessing cognitive motivation (Colorwheel/N-back \& effort discounting), reward learning (RL), motor motivation (MID), reinforcement learning and working memory (RLWM-PST) and creativity tasks (alternative uses task, remote associates task \& pasta task). The RL and MID tasks were administered in the fMRI scanner, while the other tasks were administered in three behavioural-only task blocks. In order for the fMRI data acquisition to coincide with the time-window of maximal drug effects, methylphenidate and sulpiride were administered at two different time points. To assure the experimenters were blind to the drug administered, we employed a double-dummy design (i.e., first drug administration: SUL/placebo; second drug administration: MPH/placebo). Participants received methylphenidate or placebo $90 \mathrm{~min}$ after receiving sulpiride or placebo. Data acquisition started $2.5 \mathrm{~h}$ and $0.8 \mathrm{~h}$ after sulpiride and methylphenidate administration, respectively (for drug to task timing see Table 1). Participants' food intake was standardized across the pharmaco-fMRI sessions; participants 
were offered biscuits before the ON-drug task battery started, and had a lunch we provided after the fMRI data acquisition.

Day 5

As part of the protocol of the $\left[{ }^{18} \mathrm{~F}\right]$ DOPA PET scan participant received carbidopa $(150 \mathrm{mg})$ and entacapone (400mg) $0.8 \mathrm{~h}$ before a $185 \mathrm{MBq}(5 \mathrm{mCi})\left[{ }^{18} \mathrm{~F}\right] \mathrm{DOPA}$ intravenous injection, followed by a 89 min PET acquisition. Administration of a peripheral COMT inhibitor (entacapone) and decarboxylase inhibitor (carbidopa) prior to imaging results in a marked decrease in peripheral methylation and decarboxylation of $\left[{ }^{18} \mathrm{~F}\right] \mathrm{DOPA}$, and increases its bioavailability for entry into the brain, along with a reduction in non-specific background radioactivity (Ishikawa, Dhawan, Robeson, Belakhlef, \& Margouleff, 1996). Thus, carbidopa and entacapone both act to increase the bioavailability of $\left[{ }^{18} \mathrm{~F}\right] \mathrm{DOPA}$ in the brain, thereby increasing the signal to noise ratio of the scans (Sawle et al., 1994; Cumming et al., 1995). Before the $\left[{ }^{18} \mathrm{~F}\right] \mathrm{DOPA}$ PET scan, additional baseline measures of working memory (Groth-Marnat, 2001), fluid intelligence (WAIS-IV-NL, Wechsler, 1997) were acquired, and one cognitive task was performed (Pavlovian-to-instrumental transfer task).

Between the last pharmaco-fMRI session and the $\left[{ }^{18} \mathrm{~F}\right]$ DOPA PET session participants received an online package of questionnaires to be filled out at home (off drug) to acquire additional baseline measures, such as trait impulsivity (Patton, Stanford, \& Barratt, 1995), behavioural activation/inhibition (Franken, Muris, \& Rassin, 2005, Carver \& White, 1994), need for cognition (Cacioppo, Petty, \& Kao, 1984), creativity (Kaufman, 2012), and depression (Beck et al., 1996). As an additional part of the study procedure participants could allow passive collection of coarse measures of smartphone use during a three-week period, to assess the relation between dopamine and social media app use (Westbrook, Ghosh, van den Bosch, Määttä, Hofmans \& Cools, 2021). 
DAY 2-4: PHARMACO-fMRI - TIMINGS

\begin{tabular}{|lll|}
\hline DESCRIPTION & SUL & MPH \\
Screening & & \\
Vital signs + mood & -70 & -160 \\
BEH: Colorwheel/N-BACK & -65 & -155 \\
Drug 1 (SUL/PBO) & $\mathbf{- 4 0}$ & $\mathbf{- 1 3 0}$ \\
Rest & $\mathbf{0}$ & $\mathbf{- 9 0}$ \\
Drug 2 (MPH/PBO) & 1 & -89 \\
MRI: screening & $\mathbf{8 9}$ & $\mathbf{0}$ \\
Vital signs + mood & 105 & 15 \\
BEH: Effort discounting & 120 & 30 \\
MRI: installment & $\mathbf{1 4 0}$ & $\mathbf{8 0}$ \\
MRI: RL & 170 & 80 \\
MRI: MID & $\mathbf{1 8 5}$ & $\mathbf{9 5}$ \\
Lunch & $\mathbf{2 1 5}$ & $\mathbf{1 2 5}$ \\
BEH: RLWM & 235 & 145 \\
BEH: Creativity & $\mathbf{2 5 0}$ & $\mathbf{1 6 0}$ \\
Vital signs + mood & $\mathbf{2 9 0}$ & $\mathbf{2 0 0}$ \\
Study day end & 308 & 218 \\
& 328 & 238 \\
& & \\
\hline
\end{tabular}

DAY 2-4: PHARMACO-fMRI - DRUG ORDER

\begin{tabular}{|lllc|}
\hline DAY 2 & DAY 3 & DAY 4 & No. PARTICIPANTS \\
& & & \\
MPH & PBO & SUL & 18 \\
MPH & SUL & PBO & 20 \\
PBO & MPH & SUL & 19 \\
PBO & SUL & MPH & 20 \\
SUL & MPH & PBO & 12 \\
SUL & PBO & MPH & 15 \\
& & & \\
\hline
\end{tabular}

Table 1. (Left). The order of assessments on each pharmaco-fMRI session and onset relative to drug administration (min) for sulpiride (SUL) and methylphenidate (MPH), respectively, indicated with a 0 in respective column. $\mathrm{PBO}$ : placebo; $\mathrm{BEH}$ : behavioural testing; MRI: functional magnetic resonance imaging. RL: reversal learning task; MID: monetary incentive delay task; RLWM: reinforcement learning and working memory task. (Right). Display of number of participants undergoing each of six drug administration orders.

\subsubsection{Inclusion screening}

The onsite screening assessment included a medical screening, assessing general health and vital signs, such as blood pressure (systolic BP: $95-140 \mathrm{~mm} \mathrm{Hg}$; diastolic BP: $50-95 \mathrm{~mm} \mathrm{Hg}$ ), heart rate (45-120 bpm) and electrocardiography (QTC-interval M: $<450 \mathrm{~ms} ; \mathrm{F}:<460 \mathrm{~ms}$; PR-interval: $<250 \mathrm{~ms}$ ), as well as a systematic psychiatric screening interview (M.I.N.I. Plus 5.0.0) assessing psychiatric symptoms, such as major depression, dysthymia, suicidality, (hypo) mania, panic disorder, agoraphobia, social anxiety disorder, obsessive-compulsive disorder, posttraumatic stress disorder, alcohol abuse and dependence, psychoactive substance use disorders, psychotic disorder, anorexia nervosa, bulimia nervosa, generalized anxiety disorder, and attention deficit/hyperactivity disorder. The screening was performed to ensure that participants had no diagnosis (or history) of relevant psychiatric, neurological, endocrine, or neuroendocrine treatment; presence of prolactin-dependent tumors; frequent autonomic failure; clinically significant hepatic, cardiac, obstructive respiratory, renal, cerebrovascular, cardiovascular, metabolic, ocular or pulmonary diseases/disorders; alcohol or drug dependence; epilepsy; Raynaud's syndrome; one first degree, or two or more second degree family members with history of sudden death of ventricular arrhythmia; history of over the counter medication within the last two months or prescribed medication within the last month prior to the study; regular use of corticosteroids; habitual smoking; diabetes; abnormal hearing or (uncorrected vision); glaucoma; irregular sleep/wake rhythm; possible pregnancy and no appropriate contraception. Participants also filled out a handedness inventory and an ADHD self-report questionnaire (Kooij \& Buitelaar, 1997) (Figure 1). Participants were required to abstain from cannabis throughout the course of the experiment, including 2 weeks before the start of first session, and were required to abstain from alcohol 24 hours and psychotropic medication and recreational drugs 72 hours before each 
session. Each of the following sessions started with a short screening to ensure these requirements had not been violated.

\subsubsection{Baseline measures}

Various questionnaires and assessments were administered off-drug across the study to establish participants (a) working memory capacity (Listening span \& digit span; Daneman \& Carpenter, 1980, Groth-Marnat, 2001, Listening span and digit span, respectively), (b) crystalized intelligence (NLV/NART, Crawford, Stewart, Cochrane, Parker, \& Besson, 1989; Schmand et al., 1991), (c) fluid intelligence (WAIS-IV-NL, Wechsler, 1997), (d) creativity (Kaufman, 201s2), (e) Need for Cognition (Cacioppo et al., 1984), behavioural inhibition and activation (Franken et al., 2005) (Carver \& White, 1994), (f) trait impulsivity (Patton et al., 1995) and spontaneous eye blink rate (Groman et al., 2014) (Figure 3-5). Except for the WAIS-IV-NL matrix test and the Dutch reading test (NLV/NART) all tasks were computerized. Due to an experimenter error a proto version of the trait impulsivity assessment (i.e., BIS-11A) was administered (administered in 2017-2018). After approval from the ethics committee the intended version (i.e., BIS-11) was sent out to the participants after the completion of the study, 67 out of the 100 participants completed the assessment (administered in April-May, 2020).

Spontaneous eye blink rate (sEBR) was always acquired before $5 \mathrm{PM}$ over a period of up to 10-minutes, using two vertical and two horizontal $\mathrm{Ag}-\mathrm{AgCl}$ electrodes placed around the eyes. Participants were not aware of their eye blink rate being recorded. During the course of the study SEBR acquisition time were increased from 6 to 10 minutes (28 versus 72 participants, respectively), motivated by recommendation of external colleagues (see Figure 5B). Furthermore, 10 participants received inconsistent and inaccurate instructions for the spontaneous eye blink rate acquisition (they were instructed to stare at the wall) (Figure 5B).
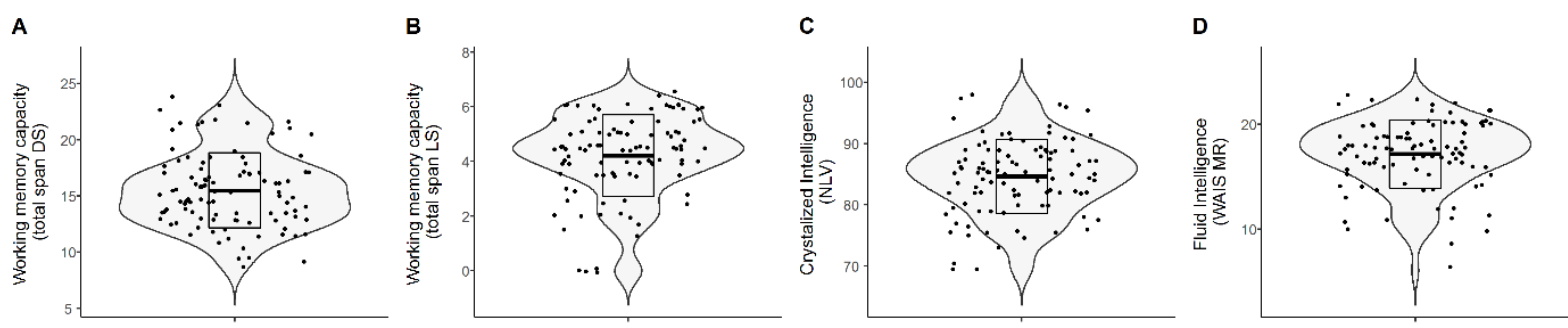

Figure 3. Neuropsychological assessments. A. Digit span score (100 participants) (Mean $=15.49, \mathrm{SD}=3.34, \min =8.500, \max$ = 24) - scores represent an average over two testing days; day $1 \& 5$ (intake \& PET session), B. Listening span (100 participants) (Mean $=4.21, \mathrm{SD}=1.49, \min =0, \max =6.5$ ), acquired on day 1 (intake). Inter-rater reliability of the independent scoring on the two working memory listening span items: listening span score and listening span recall was $\alpha=0.98$ and $\alpha=0.94$, respectively (for the latter see Supplementary Figure 1). C. NLV score (99 participants) (Mean 84.6, SD =6.04, Min = 69.5, Max $=98$ ), acquired on day 1 (intake). The inter-rater reliability of the independent scoring of the NLV score, the NLV correction and the final NLV score (including correction) was $\alpha=0.93, \alpha=1.00, \alpha=0.94$, respectively (only the latter is displayed here), D. WAIS-IV-NL (96 participants), Mean 17.16, SD = 3.25, Min =6, Max = 23), acquired on day 5 (PET session). These scores are comparable to earlier observations in the healthy population; Digit span $M=15.5$ \& Listening span $M=4.8$, NLV-IQ M = 93.6 (Froböse et al., 2018); WAIS-IV-NL matrix reasoning: $M=16.3$ (Cacciaglia et al., 2018). To see the distribution of each subscale, see supplementary material. 

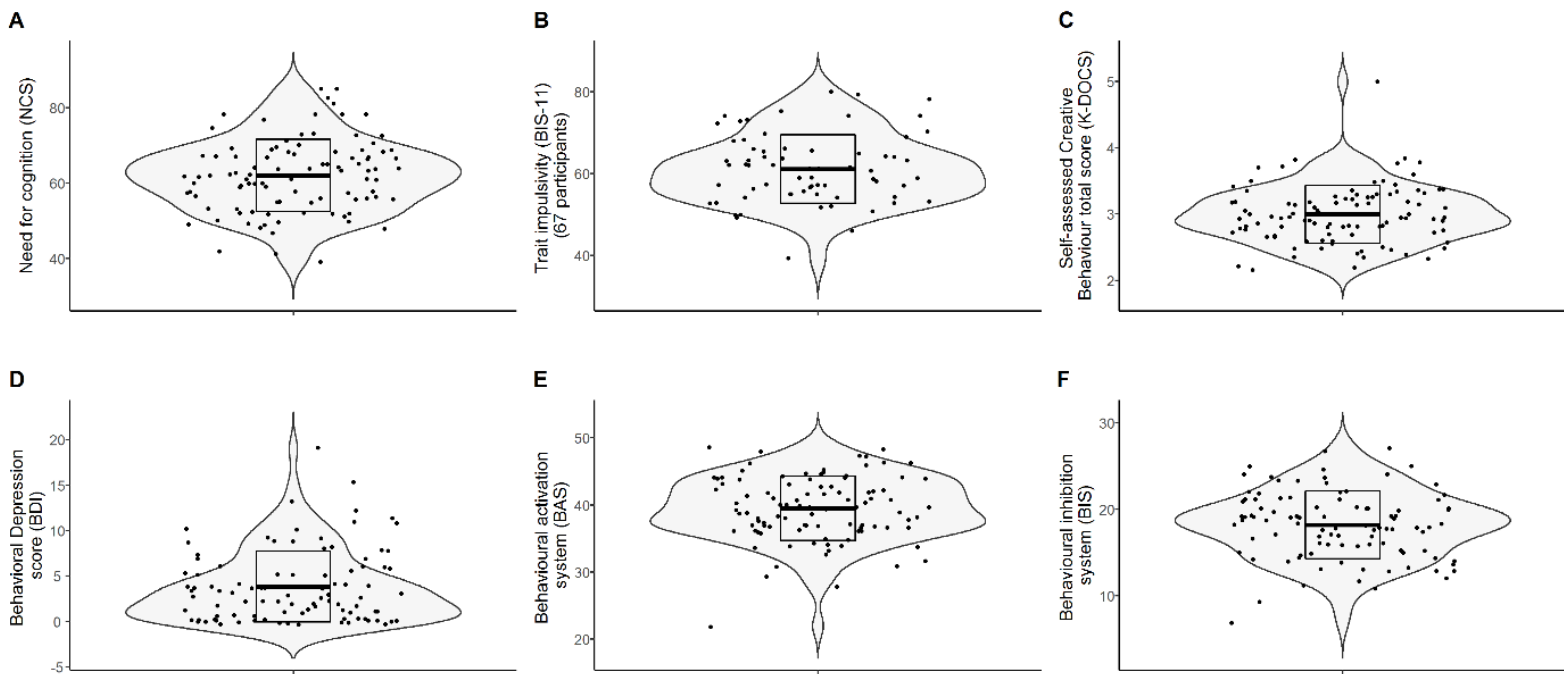

Figure 4. Self-report assessments acquired online before the last session. A. Need for Cognition scale NCS (98 participants) (Mean 62.01, SD = 9.60, Min = 39, Max =85), B. Trait impulsivity BIS-11 (67 participants) (Mean 61.13, SD = 8.37, Min = 39, $\max =80$ ), C. Self-reported creativity K-DOCS (98 participants), Mean =3.00, SD =.44, Min = 2.16, Max $=5$ ), D. Depressive symptoms BDI (98 participants) Mean $=3.85, \mathrm{SD}=3.90, \mathrm{Min}=0, \mathrm{Max}=19)$, E. Behavioural activation BAS (98 participants) Mean $=39.49, \mathrm{SD}=4.79, \mathrm{Min}=22, \mathrm{Max}=49, \mathrm{~F}$. Behavioural inhibition BIS (98 participants) (Mean 18.20, $\mathrm{SD}=3.93, \mathrm{Min}=3.93$, $\operatorname{Max}=27$ ). These scores are roughly comparable to earlier observations in the healthy population; NCS, $M=63.3 ; B I S-11, M$ = 61.8; BDI, $M=3.6$, BISBAS-BAS, $M=23.4$; BISBAS-BIS, $M=16.3$ (Froböse et al., 2018); K-DOCS, $M=3.21$ (Sutu, Serrano, Schultz, Jackson, \& Damian, 2019). To see the distribution of each subscale, see supplementary material.

A

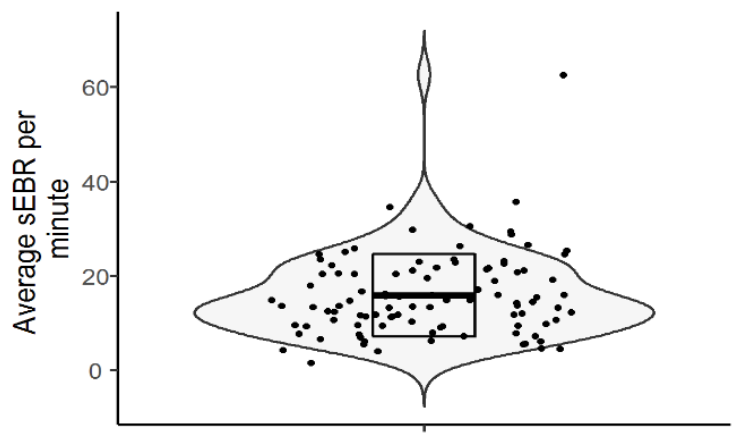

B

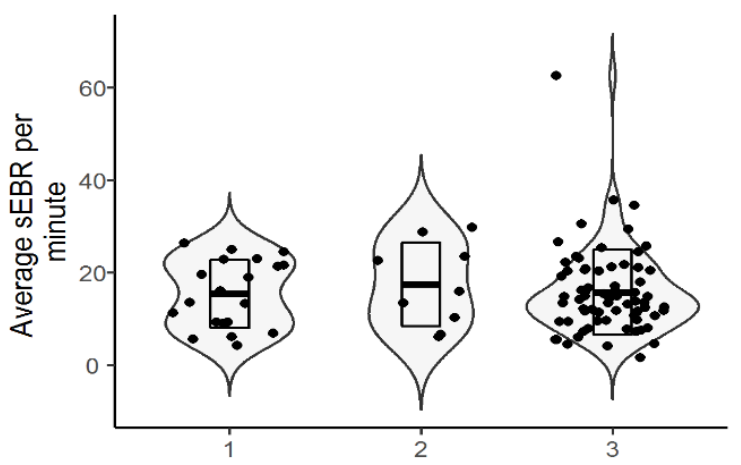

Figure 5. A. Average spontaneous EBR per minute (99 participants) (Mean 15.89, SD = 8.78, Min = 1.6, Max =62.7) comparable to other studies in a similar sample $M=14.3$ times per minute (Slagter, Georgopoulou, \& Frank, 2015). Eye blink rate was computed using automatic and manual procedures using Matlab (Slagter, Davidson, \& Tomer, 2010). The EOG data was rectified and band-pass filtered between 0.5 and $20 \mathrm{~Hz}$ using Matlab and Fieldtrip. Eye blinks were detected using an automated procedure based on a voltage change threshold set individually per participant in a time interval of $400 \mathrm{~ms}$. The VEOG signal was visually inspected by two researchers independently to assess detection accuracy. Thus, blinks were manually added or removed according to the threshold definition of a blink when appropriate, and potential artefacts from saccades or muscle activity was removed as detected in the hEOG signal. Two independent researchers scored the sEBR data. The inter-rater reliability of the independent scoring of the SEBR score was $\alpha=0.98$, therefore analyses were performed on the average of both researchers' scores. B. During the course of the study SEBR acquisition time was increased from 6 minutes (28 participants) to 10 minutes (72 participants). In total, 10 of these participants received inconsistent instructions. The distribution of the three groups are displayed in the graph: (1) 20 participants received neutral instructions where neither measurement nor blinking was mentioned (not instructed to fixate gaze) and EBR was recorded for 6 minutes ( $M=15.48$, SD = 7.36), (2) Nine participants received inconsistent instructions to fixate their gaze and were recorded for 6 minutes $(M=$ $17.55, \mathrm{SD}=9.06)$, (3) Remaining 70 participants were recorded for 10 minutes and receive neutral instructions where neither measurement nor blinking was mentioned $(M=15.80, S D=8.78)$. 


\subsubsection{Cognitive tasks}

Effects of methylphenidate and sulpiride were measured on seven cognitive tasks, administered during each of the three pharmaco-fMRI sessions. Each session started with a behavioural task paradigm where participants performed one of two effort discounting paradigms, designed to assess cognitive motivation. The first 50 participants in the sample performed an effort discounting paradigm (Papadopetraki, Froböse, Westbrook, Zandbelt, \& Cools, 2019), consisting of a colorwheel working memory task off-drug to experience different demands for working memory updating and maintenance, followed by an effort discounting task on-drug to quantify subject cost of cognitive processes with different demands for updating and maintenance (reported in Hofmans et al., 2020). The remaining 50 participants in the sample performed a working memory N-back task off-drug, followed by a gaze-discounting task on-drug (reported in Westbrook et al., 2020). The remaining task battery stayed consistent across the sample. Following the effort discounting paradigm participants performed two tasks while being scanned with fMRI: first, a reversal learning task (Cools, Altamirano, \& D'Esposito, 2006; Van der Schaaf et al., 2014 Cereb Cortex) and then a monetary incentive delay task. The reversal learning task was administered to assess the role of dopamine in updating predictions about reward and punishment, while the monetary incentive delay task was administered to assess the role of dopamine in incentive motivation (Knutson, Westdorp, Kaiser, \& Hommer, 2000; Lutz \& Widmer, 2014). Next participants performed a reinforcement learning and working memory (RLWM) task(Collins, Albrecht, Waltz, Gold \& Frank, 2017), outside the scanner, to assess the role of striatal dopamine in the interaction between reinforcement learning and working memory. Lastly, participants performed three creativity tasks, the Alternative Uses Task (AUT) administered to assess divergent creative thinking (Guilford, 1967), the Remote Associates Task (RAT) administered to assess convergent creative thinking (Mednick, 1962) and the Alternative Names Task (ANT) administered to jointly asses divergent and convergent creative thinking (Boot, Nevicka, \& Baas, 2017). The order of the three creativity tasks was counterbalanced across participants but kept constant within each participant. Additionally, on the PET session participants completed a Pavlovian-to-instrumental transfer learning paradigm (Huys et al., 2011).

\subsubsection{MRI measures}

Participants completed one anatomical T1-weighted MRI scan on the intake screening, and furthermore completed three fMRI scans across the three pharmaco-fMRI sessions. All scans were acquired with a Siemens MAGNETOM Skyra 3 Tesla MR scanner (Siemens Medical Systems, Erlangen, Germany) at the Donders Center for Cognitive Neuroimaging. The high-resolution anatomical scan was acquired using a T1-weighted magnetization prepared, rapid- acquisition gradient echo (MPRAGE) sequence (TR $2300 \mathrm{~ms}$, TE $3.03 \mathrm{~ms}, 192$ sagittal slices, $1 \mathrm{~mm}$ slice thickness, FoV 256 × 256 mm, voxel size $1 \times 1 \times 1 \mathrm{~mm}$ ). The whole-brain functional images were acquired using a 32-channel coil. A T2*weighted multi-echo echo-planar imaging (EPI) sequence was used to acquire blood-oxygen level dependent (BOLD) contrast images with 38 axial slices per functional volume (voxel size $3.3 \times 3.3 \times 3$ $\mathrm{mm}$; repetition time $2320 \mathrm{~ms}$; echo times: $9 \mathrm{~ms}, 19.3 \mathrm{~ms}, 29.6 \mathrm{~ms}$, and $39.9 \mathrm{~ms}$; flip angle = 90ㅇ ; field of view $=211 \times 211 \mathrm{~mm} ; 2.5 \mathrm{~mm}$ slice thickness, 17\% slice gap). This type of parallel acquisition sequence for functional images reduces motion and susceptibility artifacts (Poser et al., 2006). Due to a software update on the Siemens MAGNETOM SKYRA, functional imaging data were acquired with two sequences. All options of the second sequence were set to match those of the first sequence 
described above. There was only a minimal difference in the pulse frequency $(123.147865 \mathrm{MHz}$ in the first versus $123.147417 \mathrm{MHz}$ in the second sequence) and the method of acquiring the reference scan for the GRAPPA parallel imaging: the first sequence used a separate scan, whereas the second used a segmented approach.

\subsubsection{PET measures}

At the end of the study participants completed an $\left[{ }^{18} \mathrm{~F}\right] \mathrm{DOPA}$ PET scan, performed at the department of Radiology and Nuclear Medicine of the Radboud University Medical Center using a Siemens mCT PET-CT camera. Before the PET scan, a short low-dose CT scan (75 images, voxel dimensions $0.627 \mathrm{x}$ $0.627 \times 3 \mathrm{~mm}$ ) was acquired for attenuation correction. The dynamic PET scan started immediately after a bolus injection of $185 \mathrm{MBq}\left[{ }^{18} \mathrm{~F}\right] \mathrm{DOPA}$ ( $\mathrm{max} 5 \mathrm{mCi}$ ) into an antecubital vein ( $\mathrm{M}=183.87 \mathrm{MBq}, \mathrm{SD}$ $=9.96, \min =152 \mathrm{MBq}, \max =209 \mathrm{MBq})$. The dynamic acquisition frames were obtained in list mode over 89 minutes, which were reconstructed into 24 frames $(4 \times 1,3 \times 2,3 \times 3,14 \times 5$ minutes) with voxel resolution $4.073 \times 4.073 \times 3 \mathrm{~mm}$. Data were reconstructed using an ordered subset expectation maximization algorithm (21 subsets, 3 iterations) with time of flight correction, attenuation correction and correction for scatter and were smoothed with a $3 \mathrm{~mm}$ full width at half maximum kernel.

About 50 minutes $(M=53 \mathrm{~min}, \mathrm{SD}=17, \mathrm{Min}=30 \mathrm{~min}, \mathrm{Max}=170 \mathrm{~min}$ ) before the start of the PET scan participants ingested carbidopa $(150 \mathrm{mg})$ and entacapone $(400 \mathrm{mg}) .\left[{ }^{18} \mathrm{~F}\right] \mathrm{DOPA}$ PET is an in vivo marker of both aromatic amino acid decarboxylase and COMT activities. Initially, ${ }^{18} \mathrm{~F}$ radiolabelled DOPA is taken up by neutral amino acid transporters and decarboxylated to form 18F-dopamine, which is subsequently methylated by COMT and oxidized by monoamine oxidase B to form DOPAC $(3,4-$ dihydroxyphenylacetic acid) (Garnett et al., 1983; Martin et al., 1989; Leenders et al., 1990). Administration of a peripheral COMT inhibitor (entacapone) and decarboxylase inhibitor (carbidopa) prior to imaging results in a marked decrease in peripheral methylation and decarboxylation of $\left[{ }^{18} \mathrm{~F}\right] \mathrm{DOPA}$ and increases its bioavailability for entry into the brain, along with a reduction in nonspecific background radioactivity (Ishikawa et al., 1996; Leger et al., 1998). This increases the $r$ signalto noise ratio of the PET scan (Kienast et al., 2008; Stokes et al., 2012).

\subsubsection{Physiological measures}

Participants' vital signs were monitored throughout the pharmaco-fMRI sessions, including heart rate (45-120 bpm), blood pressure (systolic BP: $95-140 \mathrm{~mm} \mathrm{Hg}$; diastolic BP: $50-95 \mathrm{~mm} \mathrm{Hg}$ ) and body temperature. The measurements were taken on three occasions during each pharmaco-fMRI session, one hour before drug administration and two and five hours after drug administration, respectively. The vital signs monitoring was also used to establish whether the participant was fit to leave the center. During each vital signs' monitoring session, participants were lying down on a bed during the measurement to achieve consistent measurements. Blood pressure was consistently measured on the left arm, with the cuff placed at the level of the heart; participants were instructed to breathe normally and relax, not to talk, and not to hold their breath. Body temperature was consistently measured in the right ear. Each vital signs' monitoring was followed by a mood assessment (see section 2.2.6). 


\subsubsection{Mood assessment}

Subjective measures of mood were collected throughout the pharmaco-fMRI sessions, following the vital signs' monitoring as described in section 2.2.4. The subjective mood measures consisted of the Positive and Negative Affect Scale (PANAS) (Watson et al., 1988) and the Bond and Lader Visual Analogue Scale (VAS) (Bond and Lader, 1974). PANAS was administered to assess positive and negative affect, while the VAS was administered to assess contentedness, alertness and calmness. These subjective measures allowed us to investigate the effects of dopaminergic drugs on mood, and further to establish whether any of the cognitive effects of interests are mediated by nonspecific effects of mood.

\section{Procedures}

\subsection{Ethical approval}

The study was approved by the regional research ethics committee (Commisssie Mensgebonden Onderzoek, region Arnhem-Nijmegen; 2016/2646; ABR: NL57538.091.16) and by the board of directors of Radboud University Medical Centre for an additional feasibility approval (RvB16.51803). The study was pre-registered (trial register NTR6140, https://www.trialregister.nl/trial/5959) and carried out in accordance with the Helsinki Declaration of 1975. All participants provided written informed consent prior to participation in order to take part in the study, and provided consent to anonymously share data for research purposes. No participant retracted consent. Additional consent could be provided to take part in a smartphone application measurement and the Cognomics project (CMO2014/1294; ABR: NL49909.091.14).

\subsection{Participant recruitment}

The study was advertised online and via flyers. Interested participants received an information package after having shown interest via email. The information package included general study information regarding procedure, a brief list of exclusion criteria, the imaging techniques and the medications administered in the study. Participants were approached via phone approximately a week after they received the information package. If participants were still interested in participating in the study a short repetition of the study procedure was provided and participants were given the opportunity to ask questions, but also to verify that they did not meet any of the exclusion criteria stated in the information package. If the participant was still interested after this initial screening the participant was invited for an onsite screening before inclusion could be confirmed. The participants were informed that final inclusion could only be confirmed after the onsite screening. If participants did not meet any exclusion criteria at the onsite screening they were scheduled for the remaining four study sessions. The sessions were scheduled with minimally one week between each session in order to provide an adequate washout period for the drug. The ambition was to schedule sessions with one week a part, but to accommodate feasibility longer durations between sessions were allowed when necessary. The cognitive tests and tasks were administered in a fixed order on each session. 


\subsection{Staff training and supervision}

The staff consisted of a project coordinator, PhD students, and master students. The whole staff carried out phone screenings and cognitive testing, while intake screening was restricted to the project coordinator and PhD students who had received training. The MRI scanning training consisted of practicing to operate the scanner, monitor quality of the data and learning safety procedures. The MRI scanning was performed or supervised by a centrally trained certified MRI user who had undergone the MRI scanning training. The PET scanning was carried out by a nuclear medicine technician, including injection of $\left[{ }^{18} \mathrm{~F}\right] \mathrm{DOPA}$ and monitoring during scanning. All experimenters received a good clinical practice (GCP) training prior to or within six months after they started testing. The study coordinator and the PhD students received trained by two clinicians to perform the intake screenings, and received training on how to acquire ECG from a research nurse at the Radboud University Medical Centre. All intake screenings were supervised by a clinician before inclusion confirmation via a digital case report implemented in Castor EDC. The clinician evaluated the ECG-assessment and confirmed that the participant did (not) meet any of the exclusion criteria and all inclusion criteria. Throughout the study the clinician evaluated the relationship between reported adverse events and their potential relation to the medication and/or study procedures. All adverse events reported were mild and selflimiting. To ensure and monitor testing progress bi-weekly testing meetings were held with the staff.

To standardize screening, cognitive testing, drug administration and neuroimaging as much as possible written protocols and standard operating procedures (SOPs) for administration of screening, cognitive tests, adverse events, MRI/PET assessments and monitoring were developed. Procedures related to screening and monitoring of participants were approved by the responsible clinician. All researchers were trained on how to administer the test battery and how to perform the monitoring using the protocols before they were allowed to test independently. Each experimenter's first testing sessions were conducted under supervision of the project coordinator. Adverse events were carefully documented according to established SOPs and evaluated by the responsible physician.

\subsection{Data management and quality control}

Every participant was encoded with an anonymous identifier number to separate personal data from scientific data. Participants were initially coded with an anonymous screening number at the preliminary phone screening, and were allocated an anonymous study specific number at the time of inclusion. The data were stored separate from personal data to ensure security and privacy. Additionally, all documentation including personal data was password protected and only accessible to a limited number of researchers on the project. The data collection was documented in a digital case report file for each participant using Castor EDC (Castor EDC, 2019). Notes regarding factors that could have influenced data acquisition were carefully documented. Questionnaires were digitalized before the start of the study and were collected using Castor EDC. Castor EDC safety storage is officially certified in the field of Information Security (ISO 27001) and complies with all relevant laws and regulations (e.g., good clinical practice (GCP), general data protection regulations (GDPR), EU Annex 11). The PET imaging data were collected at the Radboud University Medical Centre, and were anonymized and de-identified before the data were made available to the researchers. Scientific data (e.g., task log files, neuroimaging data) were stored on a local server only accessible to the involved researchers, and were backed up to a data acquisition collection on Donders repository. Minimally 
processed data were made publicly available in a data sharing collection on the Donders Repository after completion of the study (available via https://doi.org/10.34973/wn51-ej53). Prior to this, all identifying information was removed to assure the privacy of our participants (e.g., records of the date of each session, date stamp of when each file was created etc.). Faces were removed from the anatomical MRI scans before being shared in the data sharing collection.

Collected data went through quality and/or sanity control checks before the data would go through to group analysis. The steps taken for analyses of each of the behavioural tasks administered are described elsewhere. Analysis requiring subjective scoring was rated independently by two researchers to establish inter-rater reliability before analysis (i.e., sEBR, NLV, LS), assessed with Cronbach's alpha (in RStudio). Acceptable inter-rater reliability was set to $\alpha>=0.90$. The scores of the independent raters that met these criteria were averaged before analysis.

\subsection{Validation of pharmacological manipulation}

Physiological measures of heart rate and blood pressure were collected together with subjective measures of mood on three time points throughout each of the three pharmaco-fMRI sessions (Table 1A). The subjective mood measures consisted of the Positive and Negative Affect Scale (PANAS) (Watson et al., 1988) and the Bond and Lader Visual Analogue Scale (VAS) (Bond and Lader, 1974). Participants had to indicate on a Likert scale whether they don't agree at all (1) or strongly agrees (5) with the feeling or emotion indicated on each item, or rate their subjective mood by moving a slider between, for example, 'tense - relaxed' to indicate how tense/relaxed they felt at the time, respectively. If participants had missed one or more item they were excluded from the analysis. The PANAS scale consists of two 10 item scales of positive and negative affect, while the visual analogue scale consists of 16 items which load on to three factors, alertness, calmness and contentedness. The higher the score the higher the alertness, calmness and contentedness. Additionally, participants rated to what extent they experienced 10 medical symptoms/complaints (e.g., headache, dry mouth, dizziness). One medical symptom item (i.e., item 4 assessing dizziness) was removed from the analysis. The rating of item 4 was presented reversed compared with the other items (i.e., higher score indicated less medical symptom), as many participants did not recognize this reverse scoring their ratings on this item were inconsistent with those on other items. To assess the effect of the drug manipulation on physiology and subjective mood we analyzed these measures with repeated measures ANOVA with factors drug (MPH vs. PBO vs. SUL) by Time (baseline (1) vs. start testing (ON drug) (2) vs. end testing (3)) using IBM SPSS version 23. Significant omnibus drug $x$ time effects were decomposed into simple (interaction) effects. We applied Bonferroni correction for multiple comparisons based on number of omnibus ANOVAs $(a=0.05 / 9=0.0056)$. The data were preprocessed and visualized using Matlab R2018b and RStudio.

\subsubsection{Drug effects on autonomic arousal}

\subsubsection{Heart rate}

The pharmacological manipulation significantly altered heart rate These effects depended on the factor time ( 3 levels: $\mathrm{T} 1=$ baseline before drug, $\mathrm{T} 2=0.5 \mathrm{~h} / 2 \mathrm{~h}$ after MPH and SUL, respectively, T3 = 3.6h/5h after MPH and SUL, respectively) (drug x time: $F(4,92)=25.11, p<.0001$ ) (Figure 6A). Similar 
to previous studies (Baas, Boot, van Gaal, de Dreu, \& Cools, 2020; Cooper et al., 2005; Volkow et al., 2003), methylphenidate increased heart rate to a greater extent than did placebo and sulpiride, but only at the end of the day. This omnibus drug by time interaction effect was due to a simple main effect at T3 $(F(2,96)=41.15, p<.00001)$, but not at T2 $(F(2,96)=.29, p=.75)$ or T1 $(F(2,96)=.47, p=.63)$. The drug effect at T3 was due to an increase in heart rate after methylphenidate compared with sulpiride $(t(95)=8.48, p<.00001)$, and also compared with placebo $(t(95)=8.20, p<.00001)$, while there was no difference between sulpiride and placebo $(\mathrm{t}(97)=-1.29, \mathrm{p}=.20)\left(\mathrm{M}_{\mathrm{MPH}-\mathrm{T}}=68.5, \mathrm{M}_{\text {sUL-тз }}\right.$ $=61.4, \mathrm{M}_{\text {Рво-тз }}=62.1$ ).

\subsubsection{Blood pressure}

Diastolic blood pressure was also altered by the pharmacological manipulation. These effects depended on the factor time ( 3 levels: T1 $=$ baseline before drug, $\mathrm{T} 2=0.5 \mathrm{~h} / 2 \mathrm{~h}$ after MPH and SUL, respectively, $\mathrm{T} 3=3.6 \mathrm{~h} / 5 \mathrm{~h}$ after MPH and SUL, respectively) (drug $x$ time: $F(4,95)=16.98, p<.00001$ ) (Figure 6B). Similar to a previous study (Volkow et al., 2003) MPH increased diastolic blood pressure to a greater extent than did placebo and SUL, but only at the end of the day. This omnibus drug by time interaction effect was due to a simple main effect at T3 $(F(4,95)=32.25, p<.0001)$, but not at $T 2$ ( $F$ $(2,96)=1.24, \mathrm{p}=.30)$ or $\mathrm{T} 1(\mathrm{~F}(2,96)=1.12, \mathrm{p}=.33)$. The drug effect at $\mathrm{T} 3$ was due to an increase in diastolic blood pressure after methylphenidate compared with sulpiride ( $t(95)=8.48, p<.0000$ ), and also compared with placebo $(t(95)=8.20, p<.00001)$, while there was no difference between sulpiride and placebo ( $\mathrm{t}(97)=-1.29, \mathrm{p}=.20)\left(\mathrm{M}_{\mathrm{MPH}-\mathrm{T}}=64.6, \mathrm{M}_{\text {sUL-Т3 }}=60.1, \mathrm{M}_{\text {Рво-Тз }}=61.4\right)$.

Systolic blood pressure was also altered by the pharmacological manipulation, and again these effects depended on the factor time ( 3 levels: T1 $=$ baseline before drug, $\mathrm{T} 2=0.5 \mathrm{~h} / 2 \mathrm{~h}$ after MPH and SUL, respectively, $\mathrm{T} 3=3.6 \mathrm{~h} / 5 \mathrm{~h}$ after MPH and SUL, respectively) (drug $x$ time: $F(4,95)=16.98, \mathrm{p}<.00001$ ) (Figure 6C). Consistent with previous studies (Baas et al., 2020; Cooper et al., 2005; Volkow et al., 2005), methylphenidate increased systolic blood pressure to a greater extent than did placebo and sulpiride. This omnibus drug by time interaction effect was due to a simple main effect at T3 $(F(4,95)$ $=32.25, \mathrm{p}<.00001)$, but not at $\mathrm{T} 2(\mathrm{~F}(2,96)=1.24, \mathrm{p}=.29)$ or $\mathrm{T} 1(\mathrm{~F}(2,96)=1.12, \mathrm{p}=.33)$. The drug effect at T3 was due to an increase in systolic blood pressure after methylphenidate compared with sulpiride (t $(95)=8.40, p<.00001)$, and also compared with placebo ( $(95)=5.10, p=.000002$ ), while there was also a marginal (but not significant) difference between sulpiride and placebo, with sulpiride marginally decreasing systolic blood pressure compared with placebo $(t(97)=-2.26, p=.026)\left(\mathrm{M}_{\mathrm{MPH}-3}\right.$ $=120.2, \mathrm{M}_{\text {sUL-T3 }}=115.2, \mathrm{M}_{\text {PBO-тз }}=116.8$.

Thus, in line with previous research we observe an overall increase in heart rate (Baas et al., 2020; Cooper et al., 2005; Volkow et al., 2003), systolic blood pressure (Baas et al., 2020; Cooper et al., 2005; Volkow et al., 2003) and diastolic blood pressure (Baas et al., 2020; Valkow et al., 2003) after methylphenidate administration, and in contrast to previous research demonstrating no effect of sulpiride on autonomic arousal (Janssen et al., 2015; Naef et al., 2017), we see a marginal (but not significant) decrease in systolic blood pressure after sulpiride, and no influence on diastolic blood pressure or heart rate. 
A Drug effects on physiology: heart rate

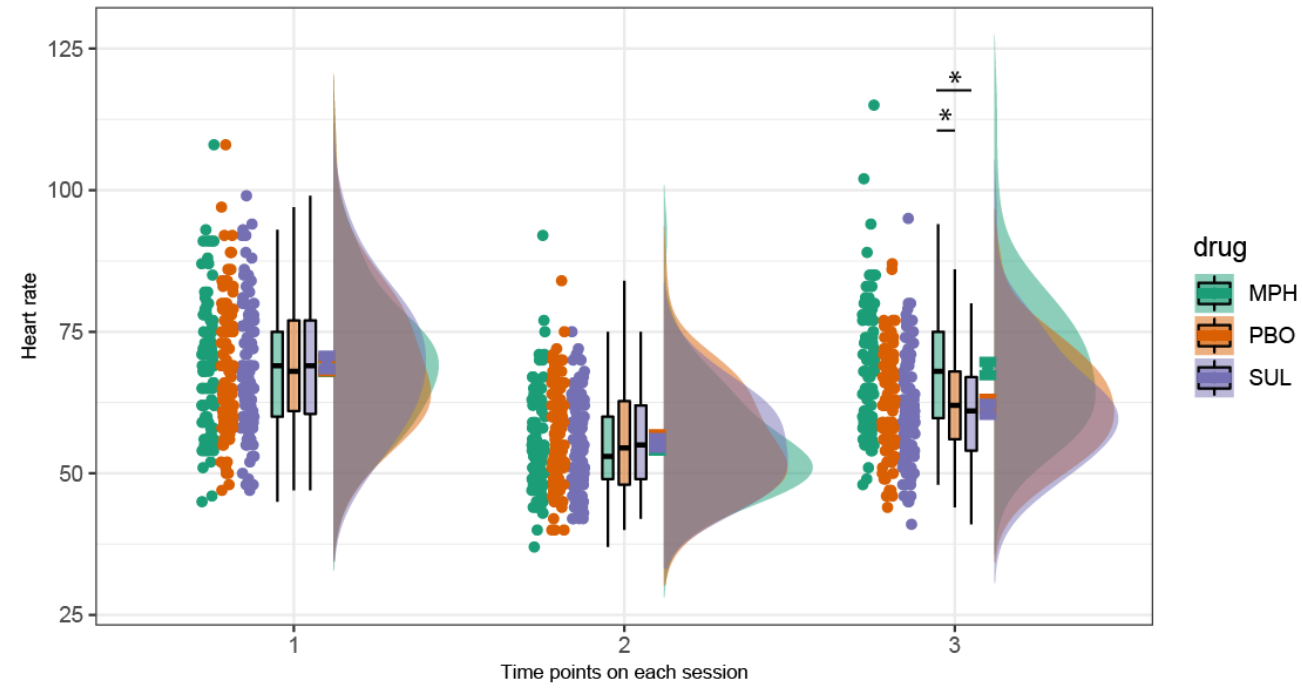

B Drug effects on physiology: diastolic blood pressure

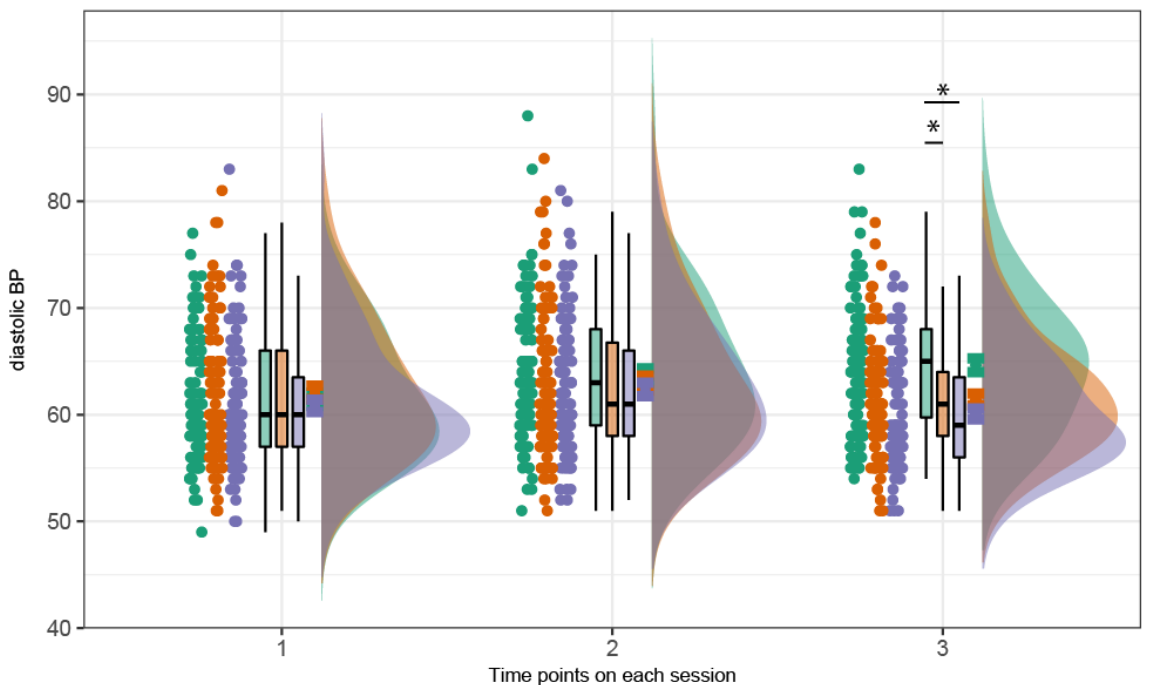

drug

MPH

PBO

sul

C

Drug effects on physiology: systolic blood pressure

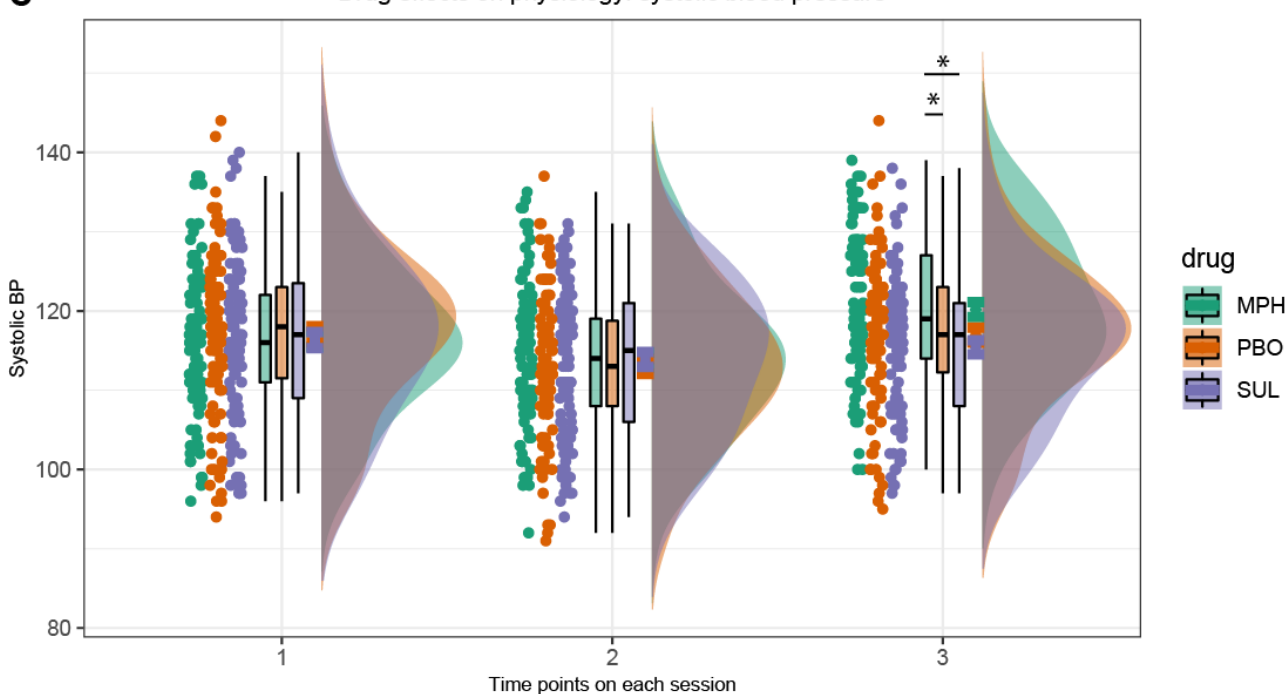

Figure 6. Mean heart rate (A) and diastolic (B) and systolic (C) blood pressure (BP) as a function of time point and drug (MPH $=$ methylphenidate; $\mathrm{PBO}=$ placebo and $\mathrm{SUL}=$ sulpiride); time point 1 , in the morning at baseline before drug intake, time point $2,0.5 \mathrm{~h}$ and $2 \mathrm{~h}$ after MPH and SUL administration, respectively and time point 3 at the end of the session, 3.6h and $5 \mathrm{~h}$ after MPH and SUL administration, respectively. 


\subsubsection{Drug effects on mood}

\subsubsection{Positive and negative affect}

As shown in Figure 7, the drugs significantly altered positive affect. These effects depended on the factor time ( $\mathrm{T} 1 \mathrm{vs} \mathrm{T} 2 \mathrm{vs} \mathrm{T} 3 ; \mathrm{T} 1=$ baseline before drug, $\mathrm{T} 2=0.5 \mathrm{~h} / 2 \mathrm{~h}$ after MPH and SUL, respectively, $\mathrm{T} 3=3.6 \mathrm{~h} / 5 \mathrm{~h}$ after MPH and SUL, respectively) (drug $x$ time: $\mathrm{F}(4,92)=8.19, \mathrm{p}<.00001$ ) (Figure 7A). As in previous research (for review see Repantis, Schlattmann, Laisney, \& Heuser, 2010), methylphenidate increased positive affect to a greater extent than placebo and sulpiride, but only at the end of the day. This omnibus drug by time interaction effect was due to a simple main effect at T3 $(F(2,95)=12.03, p$ $=.001)$, but not at $\mathrm{T} 2(\mathrm{~F}(2,96)=.46, \mathrm{p}=.63)$ or $\mathrm{T} 1(\mathrm{~F}(2,96)=103, \mathrm{p}=.36)$. The drug effect at $\mathrm{T} 3$ was due to a relative increase in positive affect after methylphenidate compared with sulpiride $(t)(95)=$ $3.38, p=.0001)$, and also compared with placebo $(t(95)=3.47, p=.001)$, while there was no difference between sulpiride and placebo $(\mathrm{t}(97)=-1.11, \mathrm{p}=.27)\left(\mathrm{M}_{\mathrm{MPH}-\mathrm{T}}=68.5, \mathrm{M}_{\text {sUL-т3 }}=61.4, \mathrm{M}_{\text {Рво-тз }}=62.1\right)$. For negative affect there was only a main effect of time $\left(F(2,92)=10.8, p=.000004\right.$.; $M_{T 1}=11.78, M_{T 2}$ $=11.25, \mathrm{M}_{\mathrm{T3}}=11.17$ ) (Figure 7B). Pair wise comparison shows that this is due to a decrease in negative affect from T1 to T2 (t $(98)=4.00, p=.0001$ ) and from T1 to T3 (t $(98)=4.21, p=.00005$ ), while there is no difference between T2 and T3 $(t(98)=1.14, p=.26)$.

\subsubsection{Visual analogous scales}

As shown in Figure 8, the drugs significantly altered alertness These effects depended on the factor time ( $\mathrm{T} 1$ vs $\mathrm{T} 2$ vs $\mathrm{T} 3$; $\mathrm{T} 1=$ baseline before drug, $\mathrm{T} 2=0.5 \mathrm{~h} / 2 \mathrm{~h}$ after MPH and SUL, respectively, $\mathrm{T} 3=$ 3.6h/5h after MPH and SUL, respectively) (drug x time: $F(4,94)=7.80, p<.000005$ ) (Figure 8A). Similar to previous studies (Repantis et al., 2010; Swart et al., 2017; van der Schaaf et al., 2013), methylphenidate increased alertness to a greater extent than did placebo and sulpiride. This omnibus drug by time interaction effect was due to a simple main effect at T3 $(F(2,96)=6.18, p=.003)$, but not at $\mathrm{T} 2(\mathrm{~F}(2,96)=.93, \mathrm{p}=.40)$ or $\mathrm{T} 1(\mathrm{~F}(2,96)=1.17, \mathrm{p}=.35)$. The drug effect at $\mathrm{T} 3$ was due to a relative increase in alertness after methylphenidate compared with sulpiride ( $t(95)=3.29, p=.001$ ), and a marginal (but not significant) increase compared with placebo (t $(94)=2.44, p=.017$ ), while there was no difference between sulpiride and placebo $(t(96)=-1.33, p=.19)\left(\mathrm{M}_{\mathrm{MPH}-\mathrm{T}}=7.03, \mathrm{M}_{\text {sUL-T3 }}\right.$ $=6.52$, Мрво-тз $=6.67)$.

The drugs also significantly altered calmness, these effects again depended on the factor time (drug $x$ time: $(F(4,92)=5.29, p=0.0004)$ (Figure 8B). As seen in previous research (Swart et al., 2017), methylphenidate decreased calmness a greater extent than did placebo and sulpiride. This omnibus drug by time interaction effect was due to a simple main effect at T3 $(F(2,96)=6.93, p=.001)$, but not at $\mathrm{T} 2(\mathrm{~F}(2,96)=1.77, \mathrm{p}=.18)$ or $\mathrm{T} 1(\mathrm{~F}(2,96)=1.33, \mathrm{p}=.27)$. The drug effect at $\mathrm{T} 3$ was due to a decrease in calmness after methylphenidate compared with sulpiride ( $t(95)=-2.91, p=.0045)$, and also compared with placebo $(t(95)=-3.34, p=.001)$, while there was no difference between sulpiride and placebo ( $\mathrm{t}(97)=-1.39, \mathrm{p}=.89)\left(\mathrm{M}_{\mathrm{MPH}-\mathrm{T3}}=7.56, \mathrm{M}_{\text {sUL-т3 }}=8.02, \mathrm{M}_{\text {Pво-тз }}=8.08\right)$. In line with previous research (Baas et al., 2020; Janssen, Sescousse, Hashemi, Timmer, et al., 2015; Naef et al., 2017; Swart et al., 2017) we observe no effects of sulpiride or methylphenidate on contentedness ( $p>.08$ ) (Figure $8 \mathrm{C})$. 
The pharmacological manipulation also affected medical symptoms (e.g., headache, dizziness, abdominal pain, joint pain, breathing difficulties), as shown by a main effect of drug $(F(2,94)=3.73$, $\left.\mathrm{p}=.026 ; \mathrm{M}_{\mathrm{MPH}}=12.05, \mathrm{M}_{\mathrm{SUL}}=11.14, \mathrm{M}_{\mathrm{PBO}}=11.62\right)($ Figure 8D). In contrast to others who have observed an increase in medical symptoms on methylphenidate compared with placebo (Swart et al., 2017), our paired sample T-tests show a marginal increase in medical symptoms on methylphenidate compared with sulpiride ( $\mathrm{t}(96)=2.56, \mathrm{p}=.012$ ), but not compared with placebo ( $\mathrm{t}(96)=1.29, \mathrm{p}=.20$ ). There was no difference between sulpiride and placebo $(t(97)=-1.63, p=.106)$. Across time, medical symptoms decreased, as revealed by a main effect of time $\left(F(2,94)=16.69, p<.0000 ; M_{T 1}=12.1, M_{T 2}\right.$ $\left.=11.42, \mathrm{M}_{\mathrm{T} 3}=11.28\right)$, which was driven by decrease on T2 versus $\mathrm{T} 1(\mathrm{t}(98)=4.02, \mathrm{p}=.0001)$ and T3 versus T1 ( $\mathrm{t}(98)=4.61, \mathrm{p}=.00001)$, but not between T2 and T3 $(\mathrm{t}(98)=1.01, \mathrm{p}=.316)$.

This pattern of findings on mood is generally consistent with previous observations following sulpiride administration (Dodds et al., 2009; Janssen, Sescousse, Hashemi, Timmer, et al., 2015; Mehta, Montgomery, Kitamura, \& Grasby, 2008; Naef et al., 2017) and methylphenidate administration (Repantis et al., 2010; Swart et al., 2017; van der Schaaf et al., 2013), except for the effect of methylphenidate on medical symptoms (Swart et al., 2017). However, note that some studies have not observed changes in alertness or mood following methylphenidate administration (Baas et al., 2020).
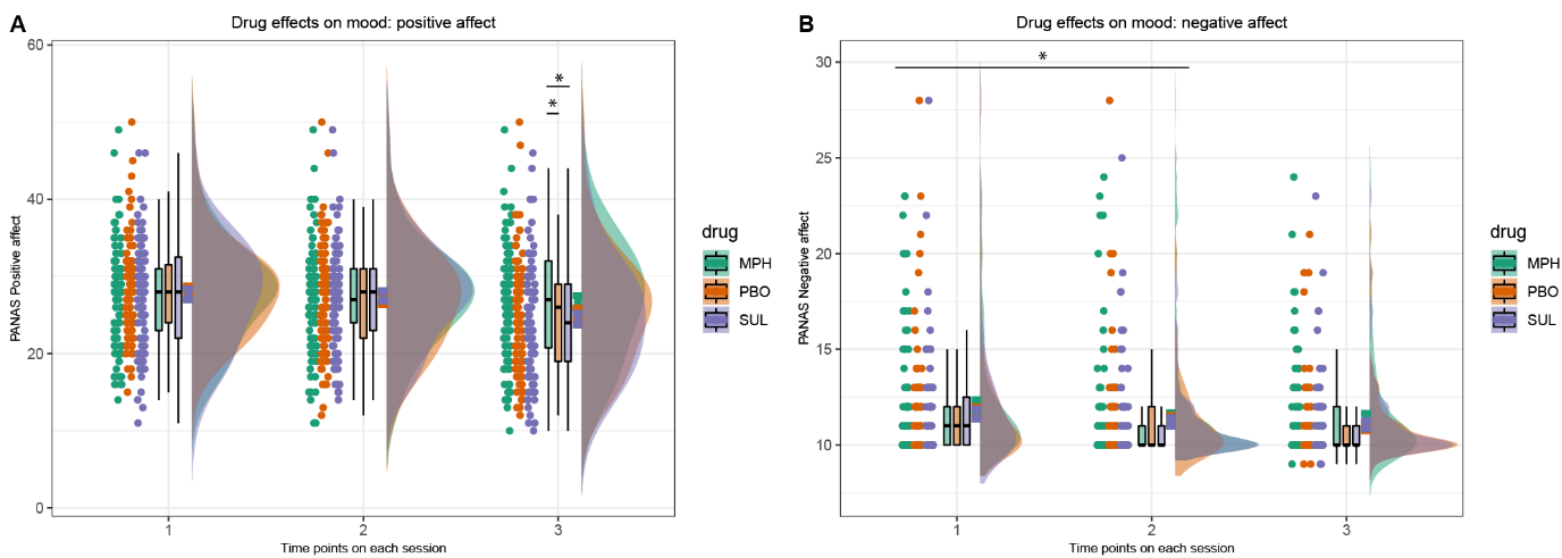

Figure 7. Positive (A) and negative affect (B) measured with PANAS, as a function of time point and drug; time point 1, in the morning at baseline before drug intake, time point $2,0.5 \mathrm{~h}$ and $2 \mathrm{~h}$ after MPH and SUL administration, respectively, and time point 3 at the end of the session, 3.6h and $5 \mathrm{~h}$ after MPH and SUL administration, respectively, 
A
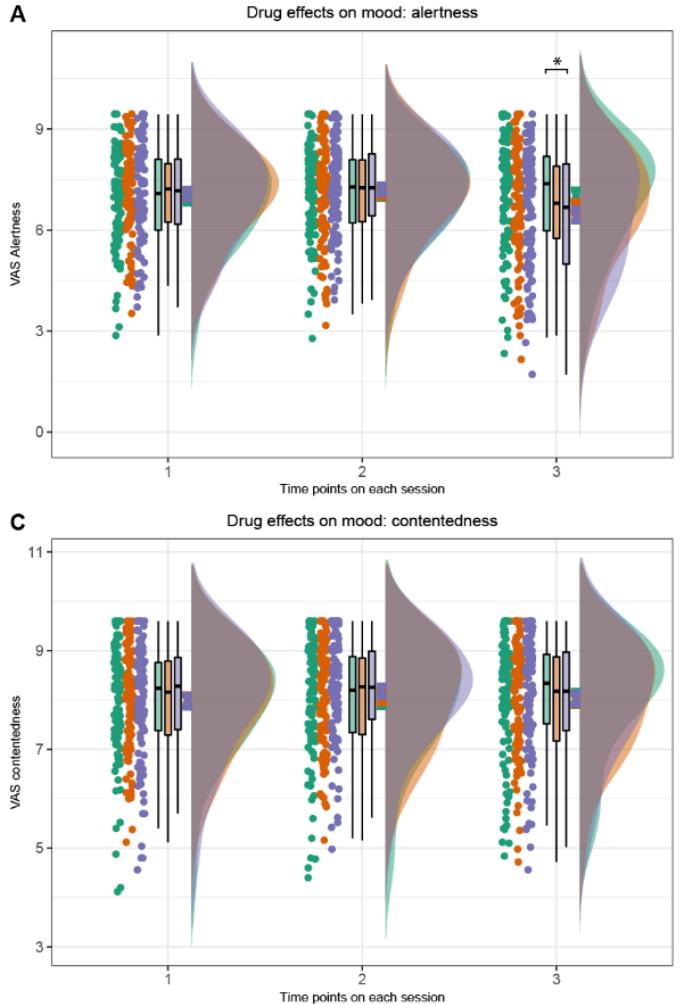

B
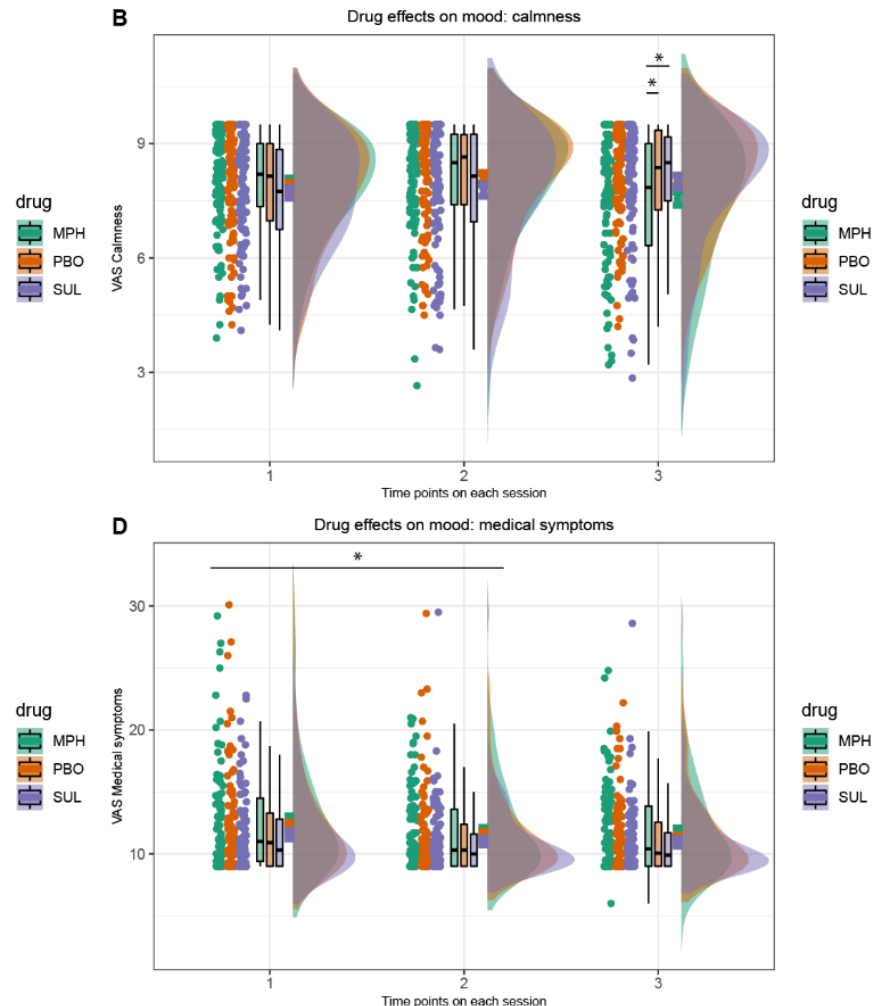

Figure 8. Subjective VAS scores of alertness (A), calmness (B), contentedness (C) and subjective medical symptoms (D), as a function of time point and drug.

\section{Data availability}

The (minimally processed) data have been made available via the Donders Repository, doi: https://doi.org/10.34973/wn51-ej53, and can be used according to the specified data use agreement RU-DI-HD-1.0 pertaining to potentially identifiable human data (see further https://data.donders.ru.nl/doc/dua/RU-DI-HD-1.0.html?4). No medical or psychiatric screening or otherwise sensitive information has been shared. Demographics other than age, gender and BMI are not shared for privacy reasons.

\section{Acknowledgment}

We thank Margot van Cauwenberg, Peter Mulder and Monique Timmer for medical assistance; Monique Timmer for psychiatric screening training; Jan Leijtens for ECG training; Ruth van Holst for analysis scripts for PET analysis; Bram Zandbelt for analysis scripts and advice on $\mathrm{fMRI}$ analysis; Monja Froboese for input during the setup of the study; Laura Barreiro for scoring sEBR; We wish to thank Heleen Slagter for kindly sharing her analysis scripts for sEBR data. The work is supported by a Vici grant awarded to Roshan Cools from the Netherlands Organisation for Scientific Research (Grant No. 453-14-015). This work will be integrated with the EBRAINS project as part of the Human Brain Project. 


\subsection{Author contributions}

RC designed and set up the study; JIM set up the study, collected data, scored sEBR, analyzed demographics, mood and physiological data, wrote the manuscript; RvB collected data; DP set up tasks, collected data; LH collected data; BL collected data; AW implemented the COGED task; RJV supervised inclusion of participants, served as medical cover during data collection. All authors revised/edited the manuscript.

\section{References}

Ago, Y., Nakamura, S., Baba, A., \& Matsuda, T. (2005). Sulpiride in combination with fluvoxamine increases in vivo dopamine release selectively in rat prefrontal cortex. Neuropsychopharmacology, 30(1), 43-51. https://doi.org/10.1038/sj.npp.1300567

Baas, M., Boot, N., van Gaal, S., de Dreu, C. K. W., \& Cools, R. (2020). Methylphenidate does not affect convergent and divergent creative processes in healthy adults. Neurolmage, 205(June 2019), 116279. https://doi.org/10.1016/j.neuroimage.2019.116279

Barnes, J. J. M., O'Connell, R. G., Nandam, L. S., Dean, A. J., \& Bellgrove, M. A. (2013). Monoaminergic modulation of behavioural and electrophysiological indices of error processing. Psychopharmacology. https://doi.org/10.1007/s00213-013-3246-y

Beck, A. T., Steer, R. A., \& Brown, G. K. (1996). Beck Depression Inventory (2nd ed.). San Antonio: The Psychological Corporation.

Berridge, C. W., Devilbiss, D. M., Andrzejewski, M. E., Arnsten, A. F. T., Kelley, A. E., Schmeichel, B., ... Spencer, R. C. (2006). Methylphenidate preferentially increases catecholamine neurotransmission within the prefrontal cortex at low doses that enhance cognitive function. Biological Psychiatry, 60(10), 1111-1120. https://doi.org/10.1016/j.biopsych.2006.04.022

Boot, N., Nevicka, B., \& Baas, M. (2017). Creativity in ADHD : Goal-Directed Motivation and Domain Specificity. Journal of Attention Disorders. https://doi.org/10.1177/1087054717727352

Brugger, S. P., Angelescu, I., Abi-Dargham, A., Mizrahi, R., Shahrezaei, V., \& Howes, O. D. (2020). Heterogeneity of Striatal Dopamine Function in Schizophrenia: Meta-analysis of Variance. Biological Psychiatry, 87(3), 215-224. https://doi.org/10.1016/j.biopsych.2019.07.008

Buckholtz, J. W., Treadway, M. T., Cowan, R. L., Woodward, N. D., Li, R., Ansari, M. S., ... Zald, D. H. (2010). Dopmainergic network differences in human impulsivity. Science, 329(532), 11-14. https://doi.org/10.1126/science.1185778.Dopaminergic

Cacciaglia, R., Molinuevo, J. L., Sánchez-Benavides, G., Falcón, C., Gramunt, N., Brugulat-Serrat, A., ... Huguet, J. (2018). Episodic memory and executive functions in cognitively healthy individuals display distinct neuroanatomical correlates which are differentially modulated by aging. Human Brain Mapping, 39(11), 4565-4579. https://doi.org/10.1002/hbm.24306

Cacioppo, J. T., Petty, R. E., \& Kao, C. F. (1984). The efficient Assessment of Need for Cognition. Journal of Personality Assessment, 48(3), 306-307.

Castor EDC. (2019). Castor Electronic Data Capture. [online] Available at: https://castoredc.com.

Chavanon, M.-L., Wacker, J., \& Stemmler, G. (2013). Paradoxical dopaminergic drug effects in extraversion: dose- and time-dependent effects of sulpiride on EEG theta activity. Frontiers in Human Neuroscience, 7(April), 117. https://doi.org/10.3389/fnhum.2013.00117 
Clatworthy, P. L., Lewis, S. J. G., Brichard, L., Hong, Y. T., Izquierdo, D., Clark, L., ... Robbins, T. W. (2009). Dopamine release in dissociable striatal subregions predicts the different effects of oral methylphenidate on reversal learning and spatial working memory, 29(15), 4690-4696. https://doi.org/10.1523/JNEUROSCI.3266-08.2009

Collins, A.G.E., Albrecth, M.A., Waltz, J.A., Gold, J.M., \& Frank, M.J. (2017). Interactions Among Working Memory, Reinforcement Learning, and Effort in Value-Based Choice: A New Paradigm and Selective Deficits in Schizophrenia. Biological Psychiatry, 82(6), 431-439. https://doi.org/10.1016/j.biopsych.2017.05.017

Collins, A. G. E., Cavanagh, J. F., \& Frank, M. J. (2014). Human EEG Uncovers Latent Generalizable Rule Structure during Learning. The Journal of Neuroscience : The Official Journal of the Society for Neuroscience, 34(13), 4677-4685. https://doi.org/10.1523/JNEUROSCI.3900-13.2014

Collins, A. G. E., \& Frank, M. J. (2012). How much of reinforcement learning is working memory, not reinforcement learning? A behavioral, computational, and neurogenetic analysis. European Journal of Neuroscience, 35(7), 1024-1035. https://doi.org/10.1111/j.1460-9568.2011.07980.x

Cools, R., Altamirano, L., \& D’Esposito, M. (2006). Reversal learning in Parkinson's disease depends on medication status and outcome valence. Neuropsychologia, 44(10), 1663-1673. https://doi.org/10.1016/j.neuropsychologia.2006.03.030

Cools, R., \& D’Esposito, M. (2011). Inverted-U-Shaped Dopamine Actions on Human Working Memory and Cognitive Control. Biological Psychiatry, 69(12), e113-e125. https://doi.org/10.1016/j.biopsych.2011.03.028

Cools, R., Frank, M. J., Gibbs, S. E. E., Miyakawa, A., Jagust, W., \& D’Esposito, M. (2009). Striatal dopoamine predicts outcome-specific reversal learning and its sensitivity to dopaminergic drug administration. J Neurosci, 29(5), 1538-1543. https://doi.org/10.1016/j.micinf.2011.07.011.Innate

Cools, R., Gibbs, S. E., Miyakawa, A., Jagust, W., \& D’Esposito, M. (2008). Working memory capacity predicts dopamine synthesis capacity in the human striatum. The Journal of Neuroscience : The Official Journal of the Society for Neuroscience, 28(5), 1208-1212. https://doi.org/10.1523/JNEUROSCI.4475-07.2008

Cools, R., Sheridan, M., Jacobs, E., \& D’Esposito, M. (2007). Impulsive Personality Predicts DopamineDependent Changes in Frontostriatal Activity during Component Processes of Working Memory. Journal of Neuroscience, 27(20), 5506-5514. https://doi.org/10.1523/JNEUROSCI.0601-07.2007

Cooper, N. J., Keage, H., Hermens, D., Williams, L. M., Debrota, D., Clark, C. R., \& Gordon, E. (2005). The dose-dependent effect of methylphenidate on performance, cognition and psychophysiology. Journal of Integrative Neuroscience, 4(1), 123-144. https://doi.org/10.1142/S0219635205000744

Crawford, J. R., Stewart, L. E., Cochrane, R. H. B., Parker, D. M., \& Besson, J. A. O. (1989). Construct validity of the National Adult Reading Test : a factor analytic study. Personality and Individual Differences, 10(5), 585-587.

Dang, L. C., O’Neil, J. P., \& Jagust, W. J. (2012). Dopamine Supports Coupling of Attention-Related Networks. Journal of Neuroscience, 32(28), 9582-9587. https://doi.org/10.1523/JNEUROSCI.0909-12.2012

Dodds, C. M., Clark, L., Dove, A., Regenthal, R., Baumann, F., Bullmore, E., ... Müller, U. (2009). The dopamine $D 2$ receptor antagonist sulpiride modulates striatal BOLD signal during the manipulation of information in working memory. Psychopharmacology, 207(1), 35-45. 
https://doi.org/10.1007/s00213-009-1634-0

Faraone, S. V, \& Buitelaar, J. (2010). Comparing the efficacy of stimulants for ADHD in children and adolescents using meta-analysis. European Child \& Adolescent Psychiatry, 19(4), 353-364. https://doi.org/10.1007/s00787-009-0054-3

Farde, L., Halldin, C., \& Sedvall, G. (1987). PET analysis of human dopamine receptor subtypes using 11C-SCH 23390 and 1 C-raclopride. Psychopharmacology, 92, 278-284.

Farde, L., Nordstrom, A.-L., Wiesel, F. -a., Halldin, C., \& Sedvall, G. (1989). D1- and D2-dopamine receptor occupancy during treatment with classical and atypical neurpleptics. Schizophrenia Research, 99, 28-31. https://doi.org/10.1016/0920-9964(90)90133-R

Frank, M. J., \& O'Reilly, R. C. (2006). A mechanistic account of striatal dopamine function in human cognition: psychopharmacological studies with cabergoline and haloperidol. Behavioral Neuroscience, 120(3), 497-517. https://doi.org/10.1037/0735-7044.120.3.497

Franken, I. H. A., Muris, P., \& Rassin, E. (2005). Psychometric Properties of the Dutch BIS / BAS Scales. Journal of Psychopathology and Behavioral Assessment, 27(1). https://doi.org/10.1007/s10862005-3262-2

Froböse, M. I., Swart, J., Cook, J., Geurts, D., HEM, D. O., \& Cools, R. (2018). Catecholaminergic modulation of the avoidance of cognitive control. J Exp Psychol Gen, 147(12), 1763-1781. https://doi.org/https://doi.org/10.1037/xge0000523

Gibbs, S. E. B., \& D'Esposito, M. (2005). Individual capacity differences predict working memory performance and prefrontal activity following dopamine receptor stimulation. Cognitive, Affective \& Behavioral Neuroscience, 5(2), 212-221. https://doi.org/10.3758/CABN.5.2.212

González-Burgos, G., Kröner, S., Krimer, L. S., Seamans, J. K., Urban, N. N., Henze, D. a., ... Barrionuevo, G. (2002). Dopamine modulation of neuronal function in the monkey prefrontal cortex. Physiology and Behavior, 77(4-5), 537-543. https://doi.org/10.1016/S00319384(02)00940-X

Groman, S. M., James, A. S., Seu, E., Tran, S., Clark, T. A., Harpster, S. N., ... Jentsch, J. D. (2014). In the blink of an eye: relating positive-feedback sensitivity to striatal dopamine D2-like receptors through blink rate. J Neurosci, 34(43), 14443-14454. https://doi.org/10.1523/JNEUROSCI.303714.2014

Groth-Marnat G (ed) (2001). The Wechsler Intelligence Scales. Cambridge University Press: Cambridge.

Guilford, J.P. (1967). The nature of human intelligence. New York: McGraw-Hill.

Hester, R., Nandam, L. S., O'Connell, R. G., Wagner, J., Strudwick, M., Nathan, P. J., ... Bellgrove, M. A. (2012). Neurochemical enhancement of conscious error awareness. The Journal of Neuroscience: The Official Journal of the Society for Neuroscience, 32(8), 2619-2627. https://doi.org/10.1523/JNEUROSCI.4052-11.2012

Hofmans, L., Papadopetraki, D., van den Bosch, R., Määttä, J. I., Froboese, M. ., Zandbelt, B. B., ... Cools, R. (2020). Methylphenidate boosts choices of mental labor over leisure depending on baseline striatal dopamine. bioRxiv. https://doi.org/https://doi.org/10.1101/859637

Howes, O. D., Egerton, A., Allan, V., McGuire, P., Stokes, P., \& Kapur, S. (2009). Mechanisms underlying psychosis and antipsychotic treatment response in schizophrenia: insights from PET and SPECT imaging. Current Pharmaceutical Design, 15(22), 2550-2559. 
https://doi.org/10.2174/138161209788957528

Huys, Q. J. M., Cools, R., Golzer, M., Friedel, E., Heinz, A., Dolan, R. J., \& Dayan, P. (2011). Disentangling the roles of approach, activation and valence in instrumental and pavlovian responding. PLoS Computational Biology, 7(4). https://doi.org/10.1371/journal.pcbi.1002028

Ishikawa, T., Dhawan, V., Robeson, W., Belakhlef, A., \& Margouleff, C. (1996). Fluorodopa Positron Emission Tomography with an Inhibitor of Catechol-O-Methyltransferase : Effect of the Plasma 3-0-Methyldopa Fraction on Data Analysis, (Ddc), 854-863.

Izquierdo, I., Bevilaqua, L., Rossato, J., Lima, R., Medina, J., \& Cammarota, M. (2008). Age-dependent and age-independent human memory persistence is enhanced by delayed posttraining methylphenidate administration. PNAS, 105(49), 19504-19507. https://doi.org/10.1073/pnas.0810650105

Janssen, L. K., Sescousse, G., Hashemi, M. M., Harmina, M., Timmer, M., Peter, N., ... Cools, R. (2015). Abnormal modulation of reward versus punishment learning by a dopamine D2-receptor antagonist in pathological gamblers, 3345-3353. https://doi.org/10.1007/s00213-015-3986-y

Janssen, L. K., Sescousse, G., Hashemi, M. M., Timmer, M. H. M., Ter Huurne, N. P., Geurts, D. E. M., \& Cools, R. (2015). Abnormal modulation of reward versus punishment learning by a dopamine D2-receptor antagonist in pathological gamblers. Psychopharmacology, 232(18), 3345-3353. https://doi.org/10.1007/s00213-015-3986-y

Jongkees, B. J., \& Colzato, L. S. (2016). Spontaneous eye blink rate as predictor of dopamine-related cognitive function-A review. Neuroscience and Biobehavioral Reviews, 71, 58-82. https://doi.org/10.1016/j.neubiorev.2016.08.020

Karson, C. N. (1983). Spontaneous eye-blink rates and dopaminergic systems. Brain, 106 (Pt 3), 643653. https://doi.org/10.1093/brain/106.3.643

Kaufman, J. C. (2012). Counting the Muses: Development of the Kaufman Domains of Creativity Scale (K-DOCS). Psychology of Aesthetics, Creativity, and the Arts, 6(4), 298-308. https://doi.org/10.1037/a0029751

Kimberg, D. Y., D’Esposito, M., \& Farah, M. J. (1997). Effects of bromocriptine on human subjects depend on working memory capacity. Neuroreport, 8(16), 3581-3585. https://doi.org/10.1097/00001756-199711100-00032

Knutson, B., Westdorp, A., Kaiser, E., \& Hommer, D. (2000). FMRI visualization of brain activity during a monetary incentive delay task. Neurolmage, 12(1), 20-27. https://doi.org/10.1006/nimg.2000.0593

Kuczenski, R., \& Segal, D. S. (1997). Effects of methylphenidate on extracellular dopamine, serotonin, and norepinephrine: Comparison with amphetamine. Journal of Neurochemistry, 68(5), 20322037. https://doi.org/10.1046/j.1471-4159.1997.68052032.x

Kuroki, T., Meltzer, H., \& Ichikawa, J. (1999). Effects of antipsychotic drugs on extracellular dopamine levels in rat medial prefrontal cortex and nucleus accumbens. The Journal of Pharmacology and Experimental Therapeutics, 288(2), 774-781. Retrieved from http://www.ncbi.nlm.nih.gov/entrez/query.fcgi?cmd=Retrieve\&db=PubMed\&dopt=Citation\&lis t_uids=9918588\%5Cnpapers3://publication/uuid/F469356D-437F-48CC-B424-8E2F0C8B53AC

Landau, S. M., Lal, R., O'Neil, J. P., Baker, S., \& Jagust, W. J. (2009). Striatal dopamine and working memory. Cerebral Cortex, 19(2), 445-454. https://doi.org/10.1093/cercor/bhn095

Li, C.-S. R., Morgan, P. T., Matuskey, D., Abdelghany, O., Luo, X., Chang, J. L. K., ... Malison, R. T. 
(2010). Biological markers of the effects of intravenous methylphenidate on improving inhibitory control in cocaine-dependent patients. Proceedings of the National Academy of Sciences of the United States of America, 107(32), 14455-14459. https://doi.org/10.1073/pnas.1002467107

Linssen, A. M. W., Sambeth, A., Vuurman, E. F. P. M., \& Riedel, W. J. (2014). Cognitive effects of methylphenidate and levodopa in healthy volunteers. European Neuropsychopharmacology, 24(2), 200-206. https://doi.org/10.1016/j.euroneuro.2013.09.009

Linssen, A. M. W., Vuurman, E. F. P. M., Sambeth, A., \& Riedel, W. J. (2012). Methylphenidate produces selective enhancement of declarative memory consolidation in healthy volunteers. Psychopharmacology, 221(4), 611-619. https://doi.org/10.1007/s00213-011-2605-9

Lutz, K., \& Widmer, M. (2014). What can the monetary incentive delay task tell us about the neural processing of reward and punishment? Neuroscience and Neuroeconomics, 33. https://doi.org/10.2147/nan.s38864

Marcus, S. C., \& Durkin, M. (2011). Stimulant adherence and academic performance in urban youth with attention-deficit/hyperactivity disorder. Journal of the American Academy of Child and Adolescent Psychiatry, 50(5), 480-489. https://doi.org/10.1016/j.jaac.2011.02.007

Mednick, S. A. (1962). The associative basis of the creative process. Psycholgoical Review, 69(3), 220232.

Mehta, M. A., Manes, F. F., Magnolfi, G., Sahakian, B. J., \& Robbins, T. W. (2004). Impaired setshifting and dissociable effects on tests of spatial working memory following the dopamine D2 receptor antagonist sulpiride in human volunteers. Psychopharmacology, 176(3-4), 331-342. https://doi.org/10.1007/s00213-004-1899-2

Mehta, M. A., McGowan, S. W., Lawrence, A. D., Aitken, M. R. F., Montgomery, A. J., \& Grasby, P. M. (2003). Systemic sulpiride modulates striatal blood flow: Relationships to spatial working memory and planning. Neurolmage, 20(4), 1982-1994. https://doi.org/10.1016/j.neuroimage.2003.08.007

Mehta, M. A., Montgomery, A. J., Kitamura, Y., \& Grasby, P. M. (2008). Dopamine D2 receptor occupancy levels of acute sulpiride challenges that produce working memory and learning impairments in healthy volunteers. Psychopharmacology, 196(1), 157-165. https://doi.org/10.1007/s00213-007-0947-0

Moeller, S. J., Honorio, J., Tomasi, D., Parvaz, M. A., Woicik, P. A., Volkow, N. D., \& Goldstein, R. Z. (2012). Methylphenidate Enhances Executive Function and Optimizes Prefrontal Function in Both Health and Cocaine Addiction. Cerebral Cortex (New York, N.Y.: 1991). https://doi.org/10.1093/cercor/bhs345

Naef, M., Müller, U., Linssen, A., Clark, L., Robbins, T. W., \& Eisenegger, C. (2017). Effects of dopamine D2 / D3 receptor antagonism on human planning and spatial working memory. Nature Publishing Group, (December 2016). https://doi.org/10.1038/tp.2017.56

Nandam, L. S., Hester, R., Wagner, J., Cummins, T. D. R., Garner, K., Dean, A. J., ... Bellgrove, M. A. (2011). Methylphenidate but not atomoxetine or citalopram modulates inhibitory control and response time variability. Biological Psychiatry, 69(9), 902-904. https://doi.org/10.1016/j.biopsych.2010.11.014

Papadopetraki, D., Froböse, M. I., Westbrook, A., Zandbelt, B. B., \& Cools, R. (2019). Quantifying the cost of cognitive stability and flexibility. bioRxiv, (453), 743120. https://doi.org/10.1101/743120

Patton, J. H., Stanford, M. S., \& Barratt, E. S. (1995). Factor Structure of the Barratt Impulsiveness 
Scale. Journal of Clinical Psychology, 51(6), 768-774.

Repantis, D., Schlattmann, P., Laisney, O., \& Heuser, I. (2010). Modafinil and methylphenidate for neuroenhancement in healthy individuals: A systematic review. Pharmacological Research, 62(3), 187-206. https://doi.org/10.1016/j.phrs.2010.04.002

Serra, G., Forgione, A., D’Aquila, P. S. ., Collu, M., Fratta, W., \& Gessa, G. . (1990). Possible Mechanism of Antidepressant Effect of L-Sulpiride. Clinical Neuropharmacology, (13), S76-S83.

Slagter, H. A., Davidson, R. J., \& Tomer, R. (2010). Neuropsychologia Eye-blink rate predicts individual differences in pseudoneglect. Neuropsychologia, 48(5), 1265-1268. https://doi.org/10.1016/j.neuropsychologia.2009.12.027

Slagter, H. A., Georgopoulou, K., \& Frank, M. J. (2015). Spontaneous eye blink rate predicts learning from negative, but not positive, outcomes. Neuropsychologia, 71, 126-132. https://doi.org/10.1016/j.neuropsychologia.2015.03.028

Spencer, R. C., Klein, R. M., \& Berridge, C. W. (2012). Psychostimulants act within the prefrontal cortex to improve cognitive function. Biological Psychiatry, 72(3), 221-227. https://doi.org/10.1016/j.biopsych.2011.12.002

Strange, P. G. (2001). Antipsychotic drugs: importance of dopamine receptors for mechanisms of therapeutic actions and side effects. Pharmacological Reviews, 53(1), 119-133.

Sutu, A., Serrano, S., Schultz, L. H., Jackson, J. J., \& Damian, R. I. (2019). Creating Through Deviancy or Adjustment? The Link between Personality Profile Normativeness and Creativity. European Journal of Personality, 33(5), 565-588. https://doi.org/10.1002/per.2215

Swart, J. C., Frobo, M. I., Cook, J. L., Geurts, D. E. M., Frank, M. J., Cools, R., \& Ouden, H. E. M. Den. (2017). Catecholaminergic challenge uncovers distinct Pavlovian and instrumental mechanisms of motivated ( in ) action. eLife, 1-36. https://doi.org/10.7554/eLife.22169

van der Schaaf, M. E., Fallon, S. J., Ter Huurne, N., Buitelaar, J., \& Cools, R. (2013). Working memory capacity predicts effects of methylphenidate on reversal learning. Neuropsychopharmacology, 38(10), 2011-2018. https://doi.org/10.1038/npp.2013.100

van der Schaaf, M. E., van Schouwenburg, M. R., Geurts, D. E. M., Schellekens, A. F. A., Buitelaar, J. K., Verkes, R. J., \& Cools, R. (2014). Establishing the dopamine dependency of human striatal signals during reward and punishment reversal learning. Cerebral Cortex, 24(3), 633-642. https://doi.org/10.1093/cercor/bhs344

Volkow, N. D., Wang, G.-J., Fowler, J. S., Logan, J., Franceschi, D., Maynard, L., ... Swanson, J. M. (2002). Relationship between blockade of dopamine transporters by oral methylphenidate and the increases in extracellular dopamine: therapeutic implications. Synapse, 43(3), 181-187. https://doi.org/10.1002/syn.10038

Volkow, N. D., Wang, G., Fowler, J. S., Logan, J., Gerasimov, M., Maynard, L., ... Franceschi, D. (2001). Therapeutic doses of oral methylphenidate significantly increase extracellular dopamine in the human brain. The Journal of Neuroscience : The Official Journal of the Society for Neuroscience, 21(2), RC121. https://doi.org/20014896 [pii]

Volkow, N. D., Wang, G. J., Fowler, J. S., \& Ding, Y. S. (2005). Imaging the effects of methylphenidate on brain dopamine: New model on its therapeutic actions for attention-deficit/hyperactivity disorder. Biological Psychiatry, 57(11), 1410-1415. https://doi.org/10.1016/j.biopsych.2004.11.006

Volkow, N.D., Wang, G.J., Fowler, J.S., Molina, P.E., Logan, J., Gately, A.G., Gifford. A., Ding, Y.S., 
Wong, C., Rappas, N.R., Zhy, W., \& Swanson, J.M. (2003). Cardiovascular effects of methylphenidate in humans are associated with increases of dopamine in brain and of epinephrine in plasma. Psychopharmacology, 166, 263-270. https://doi.org/10.1007/s00213002-1340-7

Wall, S. C., Gu, H., \& Rudnick, G. (1995). Biogenic amine flux mediated by cloned transporters stably expressed in cultured cell lines: Amphetamine specificity for inhibition and efflux. Molecular Pharmacology, 47(3), 544-550.

Westbrook, A., Ghosh, A., van den Bosch, R., Määttä, J.I., Hofmans, L., \& Cools, R. (2021). Striatal dopamine synthesis capacity reflects smartphone social activity. iScience, 1-8. https://doi.org/10.1016/j.isci.2021.102497

Westbrook, A., van den Bosch, R., Määttä, J. I., Hofmans, L., Papadopetraki, D., Cools, R., \& Frank, M. J. (2020). Dopamine promotes cognitive effort by biasing the benefits versus costs of cognitive work. Science, 367(6484), 1362-1366. https://doi.org/10.1126/science.aaz5891

Wiecki, T. V., Sofer, I., \& Frank, M. J. (2013). HDDM: Hierarchical Bayesian estimation of the DriftDiffusion Model in Python. Frontiers in Neuroinformatics, 7(August), 14. https://doi.org/10.3389/fninf.2013.00014

Wigal, S. B., Wigal, T., Schuck, S., Brams, M., Williamson, D., Armstrong, R. B., \& Starr, H. L. (2011). Academic, behavioral, and cognitive effects of $\mathrm{OROS}^{\circledR}$ methylphenidate on older children with attention-deficit/hyperactivity disorder. Journal of Child and Adolescent Psychopharmacology, 21(2), 121-131. https://doi.org/10.1089/cap.2010.0047

Yamamoto, K. ichi, Ozawa, N., Shinba, T., \& Hoshino, T. (1994). Functional influence of the central noradrenergic system on the skin conductance activity in rats. Schizophrenia Research, 13(2), 145-150. https://doi.org/10.1016/0920-9964(94)90095-7 